\title{
Universiteit
}

Leiden

The Netherlands

\section{New function of the myostatin/activin type I receptor (ALK4) as a mediator of muscle atrophy and muscle regeneration}

Pasteuning-Vuhman, S.; Boertje-van der Meulen, J.W.; Putten, M.M. van; Overzier, M.;

Dijke, P. ten; Kielbasa, S.M.; ... ; Loomans, C.J.M.

\section{Citation}

Pasteuning-Vuhman, S., Boertje-van der Meulen, J. W., Putten, M. M. van, Overzier, M., Dijke, P. ten, Kielbasa, S. M., ... Loomans, C. J. M. (2017). New function of the myostatin/activin type I receptor (ALK4) as a mediator of muscle atrophy and muscle regeneration. Faseb Journal, 31(1), 238-255. doi:10.1096/fj.201600675R

Version: $\quad$ Not Applicable (or Unknown)

License: $\quad$ Leiden University Non-exclusive license

Downloaded from: https://hdl.handle.net/1887/115140

Note: To cite this publication please use the final published version (if applicable). 


\title{
New function of the myostatin/activin type I receptor (ALK4) as a mediator of muscle atrophy and muscle regeneration
}

\author{
Svitlana Pasteuning-Vuhman, ${ }^{*}$ Johanna W. Boertje-van der Meulen, ${ }^{*}$ Maaike van Putten, ${ }^{*}$ Maurice Overzier, ${ }^{*}$ \\ Peter ten Dijke, ${ }^{\dagger \neq}$ Szymon M. Kiełbasa, ${ }^{\S}$ Wibowo Arindrarto, ${ }^{\S}$ Ron Wolterbeek, ${ }^{\$}$ Ksenia V. Lezhnina, ${ }^{\mathbb{9}}$ \\ Ivan V. Ozerov, " Aleksandr M. Aliper, "Willem M. Hoogaars," Annemieke Aartsma-Rus,, \\ and Cindy J. M. Loomans* \\ *Department of Human Genetics, ${ }^{\dagger}$ Department of Molecular and Cell Biology, ${ }^{\ddagger}$ Cancer Genomics Center, and ${ }^{\S}$ Department of Medical Statistics \\ and Bioinformatics, Leiden University Medical Center, Leiden, The Netherlands; "InSilico Medicine, Incorporated, Emerging Technology \\ Centers, Johns Hopkins University, Baltimore, Maryland, USA; and "Department of Human Movement Sciences, Faculty of Behavioral and \\ Movement Sciences, Move Research Institute Amsterdam, Vrije Universiteit Amsterdam, Amsterdam, The Netherlands
}

\begin{abstract}
Skeletal muscle fibrosis and impaired muscle regeneration are major contributors to muscle wasting in Duchenne muscular dystrophy (DMD). Muscle growth is negatively regulated by myostatin (MSTN) and activins. Blockage of these pathways may improve muscle quality and function in DMD. Antisense oligonucleotides (AONs) were designed specifically to block the function of ALK4, a key receptor for the MSTN/activin pathway in skeletal muscle. AON-induced exon skipping resulted in specific Alk4 down-regulation, inhibition of MSTN activity, and increased myoblast differentiation in vitro. Unexpectedly, a marked decrease in muscle mass $(\mathbf{1 0} \%)$ was found after Alk4 AON treatment in $m d x$ mice. In line with in vitro results, muscle regeneration was stimulated, and muscle fiber size decreased markedly. Notably, when Alk4 was down-regulated in adult wild-type mice, muscle mass decreased even more. RNAseq analysis revealed dysregulated metabolic functions and signs of muscle atrophy. We conclude that ALK4 inhibition increases myogenesis but also regulates the tight balance of protein synthesis and degradation. Therefore, caution must be used when developing therapies that interfere with MSTN/activin pathways.Pasteuning-Vuhman, S., Boertje-van der Meulen, J. W., van Putten, M., Overzier, M., ten Dijke, P., Kiełbasa, S. M., Arindrarto, W., Wolterbeek, R., Lezhnina, K. V., Ozerov, I. V., Aliper, A. M., Hoogaars, W. M., Aartsma-Rus, A., Loomans, C. J. M. New function of the myostatin/activin type I receptor (ALK4) as a mediator of muscle atrophy and muscle regeneration. FASEB J. 31, 238-255 (2017). www.fasebj.org
\end{abstract}

KEY WORDS: Duchenne muscular dystrophy · antisense oligonucleotides · myostatin/activin pathway · muscle metabolism $\cdot$ muscle mass

Myostatin (MSTN) is a member of the TGF- $\beta$ family and an inhibitor of muscle growth. It is expressed in skeletal muscle and, to a lesser extent, in adipose tissue and cardiac muscle (1-3). MSTN mainly acts via interaction with the type II receptor ACVR2B, which forms a heterodimer with the type I receptors ACVR1B (ALK4) and TGFBR1 (ALK5) $(4,5)$. The intracellular serine/threonine domains of ALK4 and -5 phosphorylate Smad2 and -3 proteins, which form a complex with Smad4 (6). This complex enters the nucleus and regulates the transcription of target genes, including

ABBREVIATIONS: 2OMePS, 2'-O-methyl phosphorothioate; Acvr2b, activin A receptor type 2B; ALK, activin A receptor kinase; ALK5, transforming growth factor $\beta$ receptor 1; ALK7, activin A receptor, type IC; Ankrd, ankyrin repeat domain; AON, antisense oligonucleotide; Asns, asparagine synthetase; Atf, activating transcription factor; Bmp, bone morphogenetic protein; $\mathrm{CD}$, cluster of differentiation; $C d k n$, cyclin-dependent kinase inhibitor; Chop, DNA damageinducible transcript 3; Col1a1, collagen type I $\alpha 1$; Cpt1b, carnitine palmitoyltransferase 1b; DMD, Duchenne muscular dystrophy; EDL, extensor digitorum longus; eMyHC, embryonic myosin heavy chain; FBS, fetal bovine serum; Fbxo, F-box protein; Gadd, growth arrest and DNA damage-inducible; Gapdh, glyceraldehyde-3-phosphate dehydrogenase; IPA, Ingenuity Pathway Analysis; Lgals3, lectin galactosidase-binding soluble 3; $m d x$, mouse model for Duchenne muscular dystrophy; MSTN, myostatin; Murf, muscle RING-finger protein; Myh, myosin heavy chain; Myh4, myosin heavy chain 4; Myog, myogenin; Pdk, pyruvate dehydrogenase kinase; qPCR, quantitative PCR; SC, serum-containing; UPR, unfolded protein response; ViM, vivomorpholino; WT, wild-type

${ }^{1}$ Correspondence: Department of Human Genetics, Leiden University Medical Center, Postzone S4-P, Albinusdreef 2, 2333 ZA Leiden, The Netherlands. E-mail: a.m.rus@lumc.nl

This is an Open Access article distributed under the terms of the Creative Commons Attribution 4.0 International (CC BY 4.0) (http://creativecommons.org/ licenses/by/4.0/) which permits unrestricted use, distribution, and reproduction in any medium, provided the original work is properly cited. 
genes involved in muscle growth, muscle metabolism, and fibrosis $(7,8)$. Lack of MSTN caused by spontaneous mutations or genetic knockout in mammals (including humans) causes skeletal muscle hyperplasia and hypertrophy. MSTN-knockout mice show improved muscle regeneration upon muscle damage $(8,9)$. Inhibition of MSTN is considered as a promising therapy for muscle-wasting disorders, including Duchenne muscular dystrophy (DMD), a lethal and common form of muscular dystrophy affecting $\sim 1$ in 5000 newborn boys worldwide $(10,11)$. Patients are wheelchair bound from $\sim 12 \mathrm{yr}$, need assisted ventilation at $\sim 20 \mathrm{yr}$, and usually die in the third or fourth decade. Several in vivo studies in $m d x$ mice (DMD mouse model) showed that MSTN inhibition was well tolerated and beneficial, with increased muscle mass and improved function $(9,12-14)$. In the past few years, blockage of the MSTN/ACVR2B pathway as a therapeutic strategy for muscular dystrophies, muscle wasting, and cachexia has been investigated in multiple clinical trials (NCT01099761, NCT01519349, NCT01423110, NCT01669174, NCT01601600, and NCT01433263) [National Institutes of Health $(\mathrm{NIH})$, Bethesda, MD, USA; $h t t p s: / / c l i n i c a l t r i a l s . g o v]$. In a clinical trial in adult patients with muscular dystrophy, MSTNneutralizing antibodies were well tolerated but had no beneficial effects on the muscles (15). Another strategy, systemic administration of a soluble form of the type II receptor ACVR2B ligand binding domain (ActRIIB-Fc), was well tolerated by healthy postmenopausal women and achieved a $5 \%$ increase in lean body mass at the highest doses (16). A subsequent phase II trial in patients with DMD was terminated because of adverse events (nose/gum bleeding) (NCT01099761), ascribed to interference of the soluble receptor with activin signaling.

We have shown that MSTN signaling occurs via the ALK4 receptor in myogenic cells and via ALK5 in nonmyogenic cells, including muscle fibroblasts (17). We also reported an antisense oligonucleotide (AON)-mediated splicing modulation strategy that could interfere with the TGF- $\beta$ signaling pathways (18). Interference was achieved by knockdown of Alk5 expression with AONs that target the in-frame exon 2 of ALK5. Treatment with these AONs decreases fibrotic gene expression and increases myogenic gene expression in $m d x$ mice. In the present study, we selectively targeted ALK4, to block MSTN/activin signaling, aiming at increasing the muscle mass in $m d x$ mice. Unexpectedly, we found that this triggered loss in muscle mass and an increase in muscle regeneration in the $m d x$ mice. In adult wild-type (WT) mice, Alk4 down-regulation resulted in an even more pronounced loss of muscle mass. To better understand the underlying mechanism, RNA sequencing (RNA-seq) analysis was performed on AON-treated WT muscles. Based on this analysis, we suggest that ALK4 signaling is a key mediator of muscle growth and wasting.

\section{MATERIALS AND METHODS}

\section{Ethics statements}

All experiments were approved by and performed according to the guidelines of the Animal Experiment Committee
(Dierexperimentencommissie) of the Leiden University Medical Center. Care was taken to limit the burden and distress for the animals as much as possible.

\section{Cell cultures and AON transfections}

Mouse myoblasts C2C12 [American Type Culture Collection (ATCC, Manassas, VA, USA)] were maintained in proliferation medium containing DMEM with $10 \%$ fetal bovine serum (FBS), $1 \%$ glucose, and $2 \%$ Glutamax (Thermo Fisher Scientific, Waltham, MA, USA) at $37^{\circ} \mathrm{C}$ with $5 \% \mathrm{CO}_{2}$. Mesenchymal stem cells C3H10 T1/2 (ATCC) were grown in $\alpha$-MEM with 10\% FBS at $37^{\circ} \mathrm{C}$ with $5 \% \mathrm{CO}_{2}$. The differentiation medium for $\mathrm{C} 2 \mathrm{C} 12$ was DMEM with $2 \%$ FBS, $1 \%$ glucose, and 2\% Glutamax. Primary myoblasts were isolated from extensor digitorum longus (EDL) muscles of 2-mo-old $m d x$ mice and digested in collagen type 1 as previously described $(19,20)$. Single myofibers were cultured on Matrigel (Corning, Nieuwegein, The Netherlands) for $3 \mathrm{~d}$ in serum-containing (SC) medium, composed of DMEM supplemented with $30 \%$ FBS, 10\% horse serum, 1\% glucose, $2 \%$ Glutamax, $1 \%$ chicken embryonic extract (Bio-Connect, Huissen, The Netherlands), $10 \mathrm{ng} / \mathrm{ml}$ basic fibroblast growth factor (Promega, Leiden, The Netherlands), and $1 \%$ penicillin-streptomycin (Thermo Fisher Scientific) at $37^{\circ} \mathrm{C}$ with $5 \% \mathrm{CO}_{2}$, allowing migration of satellite cells from isolated myofibers cultured on Matrigel. A preplating step was performed to remove muscle fibroblasts: cells were transferred to noncoated culturing flasks and incubated for $20 \mathrm{~min}$. Nonattached satellite cells were then replated on Matrigel at equal density and maintained in SC medium. Differentiation medium for primary myoblasts consisted of DMEM with $2 \%$ horse serum, $1 \%$ glucose, and $2 \%$ Glutamax. AONs with full-length phosphorothioate backbones and 2'-O-methyl-modified RNA were kindly provided by BioMarin Nederland BV (Leiden, The Netherlands). The sequences are listed in Table 1. The control AON was designed as a scrambled sequence of Alk4 AON. For transfection, we used Lipofectamine 2000 (Thermo Fisher Scientific), according to the manufacturer's instructions. In short, $\mathrm{C} 2 \mathrm{C} 12$ myoblasts were transfected with a mixture of $100 \mathrm{nM}$ AON and Lipofectamine. Separate AON-Lipofectamine dilutions were made for each AON with $3.5 \mu$ l Lipofectamine applied per 100,000 cells per $1 \mathrm{ml}$. For primary myoblasts, we used $50 \mathrm{nM}$ of each AON Lipofectamine and $2.5 \mu \mathrm{l}$ of Lipofectamine per 100,000 cells per $1 \mathrm{ml}$. Transfection was performed in penicillin-streptomycin-free differentiation medium and $4 \mathrm{~h}$ later, the medium was refreshed. C2C12 myoblasts were also transfected with vivo-morpholinos (ViMs) targeting Alk4 transcript at the final concentration of 10,5, 2 , and $1 \mu \mathrm{M}$, without any transfection reagents in the differentiation medium, and incubated for $72 \mathrm{~h}$.

\section{Myogenic differentiation assay}

C2C12 cells were plated on collagen-coated 6-well plates (for myogenic gene expression analysis) and 12-well plates (for immunofluorescence staining) at a density of 100,000 cells $/ \mathrm{ml}$ proliferation medium. After $24 \mathrm{~h}$, the cells were transfected with Alk4 or control AON with Lipofectamine. Four hours after transfection, differentiation was induced by culturing in low serum. At differentiation d 3, the cells were transfected a second time with Alk4 or scrambled Alk4 AONs. The progression of differentiation was monitored for $5 \mathrm{~d}$, after which the expression of myogenic genes was analyzed. The differentiation index was calculated as the percentage of the total number of myogenic cells that were myosin positive. Primary myoblasts isolated from $m d x$ EDL muscle were plated on Matrigel-coated 6-well plates (for myogenic gene expression analysis) at a density of 100,000 cells/ $\mathrm{ml} \mathrm{SC}$ medium. After $24 \mathrm{~h}$, the cells were transfected with ALK4 
or scrambled Alk4 AON using Lipofectamine. Four hours after transfection, myogenic differentiation was initiated by culturing in differentiation medium for $2-3 \mathrm{~d}$.

\section{Luciferase reporter assay}

C2C12 or $\mathrm{C} 3 \mathrm{H} 10 \mathrm{~T} 1 / 2$ cells were seeded at a density of 5000 cells/well on white clear bottom 96-well plates (Greiner BioOne, Alphen aan den Rijn, The Netherlands) until 70\% confluence and transiently transfected with $100 \mathrm{ng}$ (CAGA) ${ }_{12}$-Luc, $10 \mathrm{ng}$ pRL-CMV, and $200 \mathrm{nM}$ of the indicated AON with Dharmafect Duo (ThermoFisher Scientific Life Sciences). After an overnight serum starvation, cells were preincubated for $1 \mathrm{~h}$ with $10 \mu \mathrm{M}$ LY364947 (ALK4/5/7 kinase inhibitor; SigmaAldrich, Zwijndrecht, The Netherlands) as a positive control for blockage of MSTN signaling. After the preincubation, cells were stimulated with $500 \mathrm{ng} / \mathrm{ml}$ MSTN (R\&D Systems, Abingdon, United Kingdom) and/or $10 \mu \mathrm{M}$ LY364947 or serum-free medium for $8 \mathrm{~h}$. The cells were lysed with the DualGlo Luciferase Assay Kit (Promega, Leiden, The Netherlands), and luciferase signals were read in the Multilabel Counter (Perkin Elmer, Waltham, MA, USA). Renilla luciferase signals served to normalize for transfection efficiency.

\section{ViM treatment in mice}

For animal experiments, ViM counterparts of the most efficient Alk4 AON were purchased from Gene-Tools (Philomath, OR, USA). Sequences are listed in Table 1 . Mice were bred by the animal facility of the Leiden University Medical Center and kept in ventilated caged with $12 \mathrm{~h}$ of light dark cycles. Mice were age and gender matched and were randomized over the experimental groups. Investigators performing the analyses were blinded to experimental group. Gastrocnemius and tibialis anterior muscles of 4-wk-old male $m d x$ or 3-mo-old male C57BL/6Jico WT mice were injected with $40 \mu \mathrm{g}$ ALK4 ViM or control nontargeting ViM at the same dose. Mice were anesthetized with $2 \%$ isoflurane, intramuscularly injected on 2 consecutive days, and euthanized $1 \mathrm{wk}$ (short-term treatment) or $7 \mathrm{wk}$ (long-term treatment) after the first injection. Long-term treatment included an extra injection $4 \mathrm{wk}$ after the first injection. Gastrocnemius and tibialis anterior muscles were isolated and snap frozen in 2-methylbutane (SigmaAldrich) cooled in liquid nitrogen. Sections of $8 \mu \mathrm{m}$ were obtained with a microtome used for RNA isolation and histologic analyses.

\section{In vivo force measurements of tibialis anterior muscles}

The same long-term, 3-injection protocol was used for the tibialis anterior muscles as for the gastrocnemius muscles. Each mouse was anesthetized with $2 \%$ isoflurane $7 \mathrm{wk}$ after the first intramuscular Alk4 ViM or control ViM injection (21). In short, the tendon of the tibialis anterior was exposed and freed, after which a thread was tightly secured and tied into a loop. The sciatic nerve was located, and all branches of the nerve were cut while keeping the common peroneal nerve, which stimulates the tibialis anterior, intact. The mouse was placed on a rig, and the leg was immobilized by a needle stuck between the patella and the knee and secured in the rig setup, while the foot was secured with tape. In this way, any unwanted movements of the leg were prevented. The tendon was attached via a homemadeS-hook to the lever arm of the force transducer, and the distal part of the peroneal nerve was stimulated with bipolar platinum electrodes. Data were acquired with a Lab-View-based DMC program (Dynamic Muscle Control and Data Acquisition; Aurora Scientific, Aurora, ON, Canada). After an initial warmup ( 5 stimulations of $50 \mathrm{~Hz}$ spaced 1 min apart), optimal muscle length $\left(L_{0}\right)$ was determined by a series of twitches at increasing resting tension. Maximum isometric tetanic force $\left(P_{\mathrm{o}}\right)$ was determined from the plateau of the force-frequency relationship after a series of stimulations at 10 , $30,40,50,80,100,120,150$, and $180 \mathrm{~Hz}$, spaced 1 min apart. The specific force $\left(\mathrm{N} / \mathrm{cm}^{2}\right)$ was determined by dividing $P_{\mathrm{o}}$ by muscle cross-sectional area. Overall cross-sectional area was estimated with the following formula: muscle weight $(\mathrm{g}) /[\mathrm{TA}$ fiber length $\left.\left(L_{\mathrm{f}} ; \mathrm{cm}\right) \times 1.06 \mathrm{~g} / \mathrm{cm}^{3}\right]$. Specific isometric force was determined by dividing the absolute force at each stimulation frequency by the muscle's cross-sectional area. After a resting period of $5 \mathrm{~min}$, the susceptibility of tibialis anterior muscles to contractioninduced injury was measured (21). The muscles were stimulated at $120 \mathrm{~Hz}$ for $500 \mathrm{~ms}$ before lengthening at $10 \%$ of $L_{\mathrm{o}}$ at a velocity of $0.5 L_{\mathrm{o} \mathrm{s}} \mathrm{s}^{-1}$. At the end of the stimulation, the muscle was returned to $L_{\mathrm{o}}$ at a rate of $-0.5 L_{\mathrm{o}} \mathrm{s}^{-1}$. The stimulation-stretch cycle was repeated every $2 \mathrm{~min}$ for a total of 10 cycles. The maximum isometric force of the second contraction was used as $100 \%$ baseline. After the procedure, the muscles were isolated, weighed, and prepared for RNA analysis.

\section{RNA isolation, RT-PCR, and quantitative PCR}

Muscle tissues were sectioned with a cryotome, and the sections were collected in 1.4-mm zirconium bead-prefilled tubes (OPS Diagnostics, Lebanon, NJ, USA). Muscle tissue was homogenized in TriPure isolation reagent (Roche Diagnostics, Basel, Switzerland), with a MagNA Lyser (Roche Diagnostics). Total RNA was isolated by the TriPure isolation method, and the RNA was further cleaned up by applying a NucleoSpin RNA II kit (Macherey-Nagel, Düren, Germany), according to the manufacturer's instruction. cDNA was synthesized from 0.5 to $1 \mu \mathrm{g}$ of RNA using random N6 primers (Thermo Fisher Scientific) and Bioscript enzyme (GCBiotech, Alphen aan den Rijn, The Netherlands) according to the manufacturer's instructions. For exon skip analysis, 10 times diluted cDNA was amplified by PCR with FastStart Taq DNA Polymerase (Roche Diagnostics) followed by use of the Lab-on-a-Chip system (Agilent Technologies, Santa Clara, CA, USA), to measure exon skip levels (22). Quantitative PCR (qPCR) was performed in triplicate per biologic sample, with LightCycler 480 and the ready-to-use SensiMix reagents (GCBiotech). The expression levels were analyzed by applying the LinReg qPCR method and normalized to expression values of the housekeeping genes Gapdh and Hbms. We confirmed that their expression values did not vary between time points and animal models. Primer sequences and detailed PCR conditions

TABLE 1. Sequences of 2OMePS AONs and ViMs

\begin{tabular}{llll}
\hline \hline Name & Chemistry & Target gene/exon & \multicolumn{1}{c}{ Sequence, 5'-3' } \\
\hline Alk4 AON & 2OMePS & Alk4/exon6 & UGACUUCAAGUCUCGAUGAGC \\
ScrAlk4 AON & 2OMePS & Nontargeting & CUAGGUCAAUCGAUGCUUGAC \\
Alk4 ViM & ViM & Alk4/exon6 & TCTATGGTGTCAGTGACCGCATCAT \\
Control ViM & ViM & Nontargeting & CCTCTTACCTCAGTTACAATTATA \\
\hline
\end{tabular}


will be provided on request. The exon skip levels were quantified with the Lab-on-a-Chip system (22).

\section{Sanger sequence analysis}

RT-PCR products were isolated from $2 \%$ agarose gels with the QiaQuick Gel Extraction Kit (Qiagen). Direct DNA sequencing took place in the Leiden Genome Technology Center, with the BigDye Terminator Cycle Sequencing Ready Reaction kit. Analysis was performed on an ABI 3730 Sequencer (both from Thermo Fisher Scientific).

\section{RNA sequencing}

Total RNA was extracted from the gastrocnemius muscles isolated from WT mice treated with ALK4 $(n=6)$ or control $(n=6)$ $\mathrm{ViM}$ for $7 \mathrm{wk}$. The RNA integrity number was $>7.8$ for all samples. RNAseq was performed at the Leiden Service XS Sequencing Center on an HiSeq 2500 sequencer (Illumina, San Diego, CA, USA) that included sample preparation, library validation and extensive data quality control and filtering. All 12 samples underwent paired-end sequencing on the same lane. The resulting raw reads were first analyzed using FastQC v0.10.1 (Brabraham Bioinformatics, Cambridge, United Kingdom; http:// wwww.bioinformatics.babraham.ac.uk/projects/fastqc/ ). If a read pair was found to contain any known sequencing adapters, as shown by the FastQC overrepresented sequence module, the full adapter sequences were clipped with cutadapt v1.5, setting the minimum length flag to 20 . Read pairs clipped this way were synchronized with their counterparts by using a custom tool to ensure that the pairing remained correct. Reads were subjected to base quality trimming with the default options of Sickle, v. 1.33 (https://github.com/najoshi/sickle/). The resulting reads served as an input for alignment. The reads were aligned to the Mus musculus mm10 genome sequence, with GSNAP, http:/ / www.gvst.co.uk/ gsnap.htm, v. 2014-12-23, setting the -npaths flag to 1 and the quiet-if-excessive flag to ensure unique and only unique alignments. The generated alignment file was compressed to BAM and then name-sorted using Picard 1.120 (Broad Institute, Boston, MA, USA (https://github.com/broadinstitute/picard/). Fragment count per gene was generated using HTSeq-count v0.6.1.p1, setting the stranded flag to no and -order flag to name and using the GTF of the RefSeq gene annotation prepared from the table browser (University of California, Santa Cruz, Santa Cruz, CA, USA; https://www. genome.ucsc.edu/). Finally, a single table with fragment counts for all samples was prepared and used for differential expression analysis.

\section{Differential expression and pathway analyses}

Fragment counts were analyzed for differential expression between ALK4- and control ViM-treated groups. Because only 2 subjects were measured in both groups, we used 2-group comparison models. The analysis was performed on 10,541 genes for which the average CPM was above 4 . We used $3 \mathrm{R}$ Bioconductor packages for differential expression analysis, (i.e., DESeq2, limmavoom and edger), following their guidelines (http:/ / www. bioconductor.org/help/workflows/rnaseqGene/). Genes consistently reported as differentially expressed by all 3 packages were used in further analysis. The KEGG pathway gene sets were tested for association with the group variable using the R Bioconductor global test package $(23,24)$. In addition to the KEGG-based pathway analysis, the OncoFinder method was used $(25,26)$. We also identified biologic pathways and networks through Ingenuity Pathway Analysis (IPA; Qiagen, Redwood, CA, USA). The list of differentially expressed genes was imported into IPA and based on the differentially expressed values that IPA divided genes into (i.e., up- and down-regulated genes). Biologic pathways, that were most affected by the treatment were identified with the Fisher exact test $(P<0.05)$. The upstream regulator analysis algorithm identified main upstream regulators and transcriptional factors. All 3 pathway analyses were performed on counts normalized with limma-voom.

\section{Muscle histology and morphology}

Frozen muscle sections ( $8 \mu \mathrm{m}$ thickness) were cut with a cryotome and fixed in ice-cold acetone for $5 \mathrm{~min}$. For measuring the fibrotic area, gastrocnemius muscle sections were stained with hematoxylin and eosin (Sigma-Aldrich) and mounted in Permount mounting medium (Histolab, Västra Frölunda, Sweden), according to conventional methods. The stained sections were examined under a light microscope (LeicaDMLB; Leica Microsystems, BV, Son, The Netherlands) at $\times 10$ magnification. Images were taken with a Leica DC500 camera and Leica IM50 software (Leica Microsystems). The fibrotic/necrotic percentage of the entire cross section was determined with the freely available ImageJ software (NIH) $(27,28)$. Fiber size was measured with SMASH (Matlab based analysis; MatLab, Natick, MA, USA) (29). For these analyses, gastrocnemius muscle sections were fixed with ice-cold acetone and stained with a laminin primary antibody (ab11575, dilution 1:200; Abcam, Cambridge, MA, USA) overnight at $4^{\circ} \mathrm{C}$ and with a goat-anti-rabbit Alexa 594 secondary antibody (A11012, dilution 1:1000; Thermo Fisher Scientific) and DAPI for $1.5 \mathrm{~h}$ at room temperature. Sections were imaged with an SP5 or SP8 confocal microscope (Leica) at a $\times 10$ magnification. At least 7-10 microscopic views were counted and analyzed, resulting in an average total number of 5000-7500 fibers per muscle. The minimum fiber area was set at $50 \mu \mathrm{m}^{2}$ and the maximum fiber area was set at $10,000 \mu \mathrm{m}^{2}$. The relative number of fibers in specified bins were counted and the results depicted in histograms. Percentages of regenerative areas were measured with ImageJ analysis by dividing the total embryonic myosin heavy chain (eMHC)-positive area by the total tissue area on stitched gastrocnemius muscle sections. For these analyses, gastrocnemius muscle sections were stained with an eMHC primary antibody (F1.652, dilution 1:100; Developmental Studies Hybridoma Bank, Iowa City, IA, USA) overnight at $4^{\circ} \mathrm{C}$ and with a goat anti-mouse Alexa 488 secondary antibody (A11001, dilution 1:1000; Thermo Fisher Scientific) and DAPI for $1.5 \mathrm{~h}$ at room temperature. Images of the stained muscle sections were taken with an SP5 or SP8 confocal microscope (Leica) at a $\times 10$ magnification and stitched with the Leica software LASFx. Fibertype switch analyses were performed with ImageJ software on a whole (stitched) gastrocnemius muscle section. Nonfixed frozen sections were stained with a laminin primary antibody (ab11575, dilution 1:200; Abcam) for $1 \mathrm{~h}$ at room temperature and with a donkey-anti rabbit Alexa 647 secondary antibody for $1 \mathrm{~h}$ at $4^{\circ} \mathrm{C}$. Thereafter, slides were stained with directly conjugated fiber-type-specific antibodies: Type 1 antibody BA-D5-Alexa 350 (1:300), Type 2A antibody SC-71-Alexa594 (1/900), and Type 2B antibody BF-F3 ${ }^{-A l e x a 488}(1: 600)$ overnight at $4^{\circ} \mathrm{C}$ (antibodies kindly provided by Prof. D. J. Wells, Royal Veterinary College, London, United Kingdom). Conjugation was performed according to the manufacturer's instructions with Alexa Fluor 350, 488, and 594 Protein labeling kits (Thermo Fisher Scientific). Images of the stained muscle sections were obtained with an SP5 or SP8 confocal microscope (Leica) at $\times 10$ magnification, and images were stitched with Leica software. The percentage of fiber-type-positive areas was divided by the total muscle area.

\section{Statistical analyses}

Data were analyzed by using Prism 4 (GraphPad Software, La Jolla, CA, USA) and SPSS 17.0.2 (IBM, Armonk, NY, USA). Values 
are presented as means $\pm \mathrm{SD}$. Data from Alk4 and control-treated muscles were compared by Student's $t$ test. In studies that involved only a comparison between the left and right gastrocnemius or tibialis anterior muscle, a paired Student's $t$ test was used to determine statistical significance. For physiologic analysis of tibialis anterior muscles, repeated-measures ANOVA and multiple comparisons with Bonferroni were used. To access fiber size distribution, 2 different statistical tests were conducted with SPSS: logistic regression to demonstrate the switch toward smaller fiber sizes for Alk4 ViM treatment; and mixed model for WT samples and a paired Student's $t$ test for $m d x$ samples, to access significant differences in mean fiber area between control and Alk4 ViM-treated muscles. Statistical significance was set at $P<0.05$.

\section{RESULTS}

\section{AON-mediated exon skipping of Alk4 enhances myogenic differentiation in vitro}

An AON-mediated exon skipping strategy was developed to selectively block the function of the ALK4 receptor. AONs with specific sequences to target the out-of-frame exon 6 were designed by a published protocol (30), resulting in the skipping of this exon and knockdown of Alk4 transcript. Newly designed AONs with phosphorothioate backbones and 2'-O-methyl ribose modifications (2OMePS) were used in our in vitro study. The efficiency of each AON was assessed by measuring exon-skipping levels and transcript down-regulation after transfection in $\mathrm{C} 2 \mathrm{C} 12$ myoblasts. The most efficient AON was selected for further studies (data not shown), and a scrambled control for it was designed (henceforth referred to as Alk4 and control AON, respectively). Alk4 AON, but not the control AON, efficiently induced exon 6 skipping after transfection in $\mathrm{C} 2 \mathrm{C} 12$ myoblasts as measured by RT-PCR analysis with primers flanking the target exon 6 (Fig. 1A). Sequencing of the PCR skip product showed that the targeted exon 6 was excluded (Fig. 1B). In addition, a specific $40 \%$ decrease in Alk4 full-length transcript was measured by real-time qPCR analysis with primer pairs both inside and outside exon 6 (Fig. 1C). Alk4 AON led to a specific transcript down-regulation as Alk5 expression did not differ between control and Alk4 AON-transfected C2C12 cells, whereas Alk7 was not expressed by C2C12 cells (data not shown). Next, we studied the effect of Alk4 AON on protein level and function. Because of a lack of specific ALK4 antibodies, we looked at the downstream effects of Alk4 AON-mediated knockdown and its ability to block MSTN signaling in vitro. In a previous study, we found that MSTN signaling is mediated via ALK4 in myogenic cells and via ALK5 in nonmyogenic cells using siRNAs (17). In the present study, C2C12 myoblasts and C3H10T1/2 cells (nonmyogenic cells) were cotransfected with Alk4 AON and a (CAGA)12-luciferase transcriptional reporter construct that drives expression of a luciferase reporter gene in a Smad3-dependent manner $(17,31)$. Alk4 AON blocked the MSTN signaling in $\mathrm{C} 2 \mathrm{C} 12$ cells, but exerted no effect on the C3H10T1/ 2 cells (in which MSTN signals via ALK5). The ALK4/5/7 kinase inhibitor LY364947 served as a positive control for blocking MSTN signaling in both cell lines (Fig. 2A).
Figure 1. Alk4 AON targets the out-of-frame exon 6 and results in efficient exon 6 skipping and Alk4 knockdown in C2C12 myoblasts. A) AON targeting exon 6 of Alk4 (Alk4 AON) and scrambled control AON were transfected at $100 \mathrm{nM}$ concentration into C2C12 murine myoblasts. RNA was isolated after $24 \mathrm{~h}$, and the efficiency of exon-skipping induction was measured by RT-PCR using Alk4-specific primers in flanking exons (arrowheads). B) Sequencing of the PCR products showed exclusion of the target exon 6 (exon 6 skip). C) qPCR was performed to measure full-length Alk4 transcript expression using primers in the skipped exon to assess Alk4 transcript down-regulation. Alk5 transcript expression was measured by $\mathrm{qPCR}$ and remained unchanged in Alk4 AON-treated C2C12.The data are presented as the average of the results of 3 independent experiments normalized to Gapdh and are shown relative to control AON samples. Error bars, SD.
A

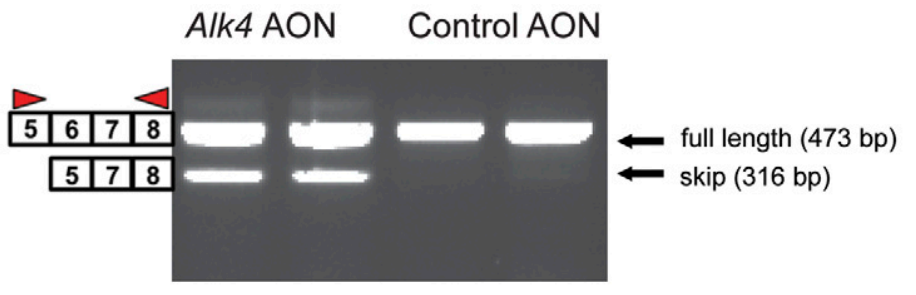

B
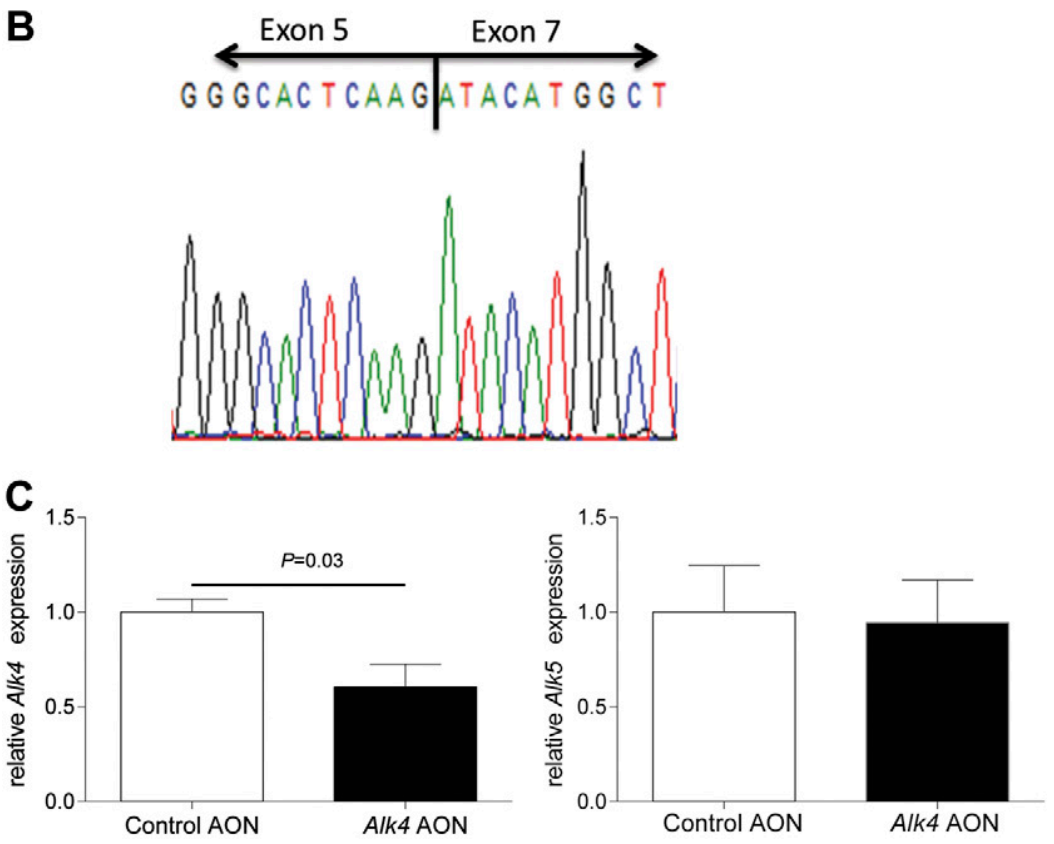

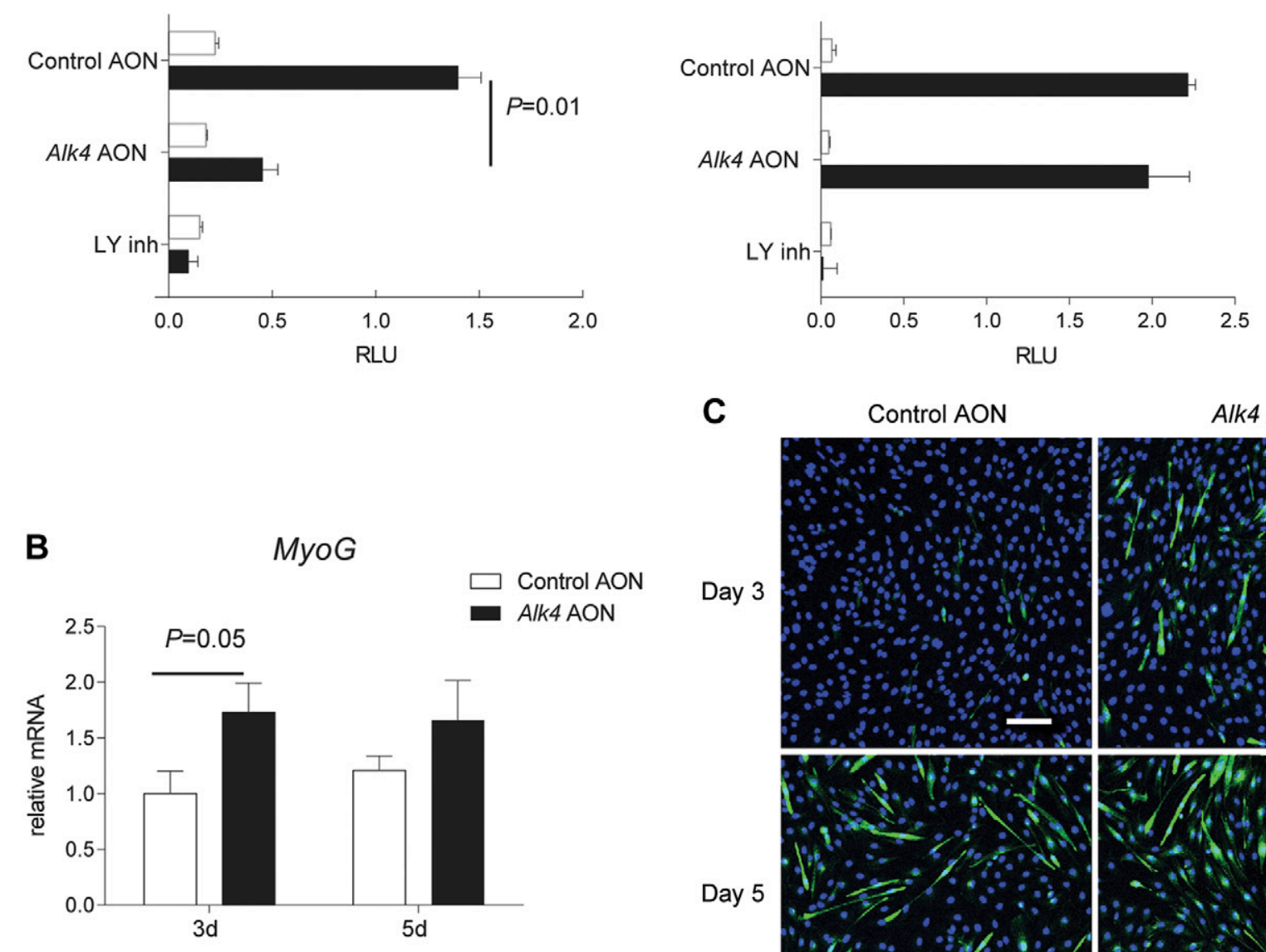

\section{C}
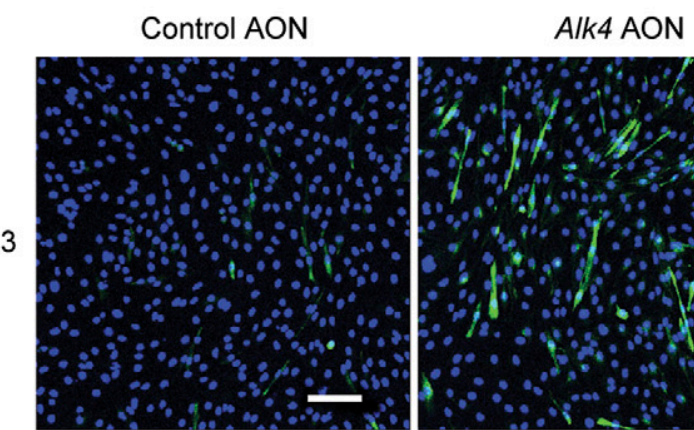

Day 3

Day 5
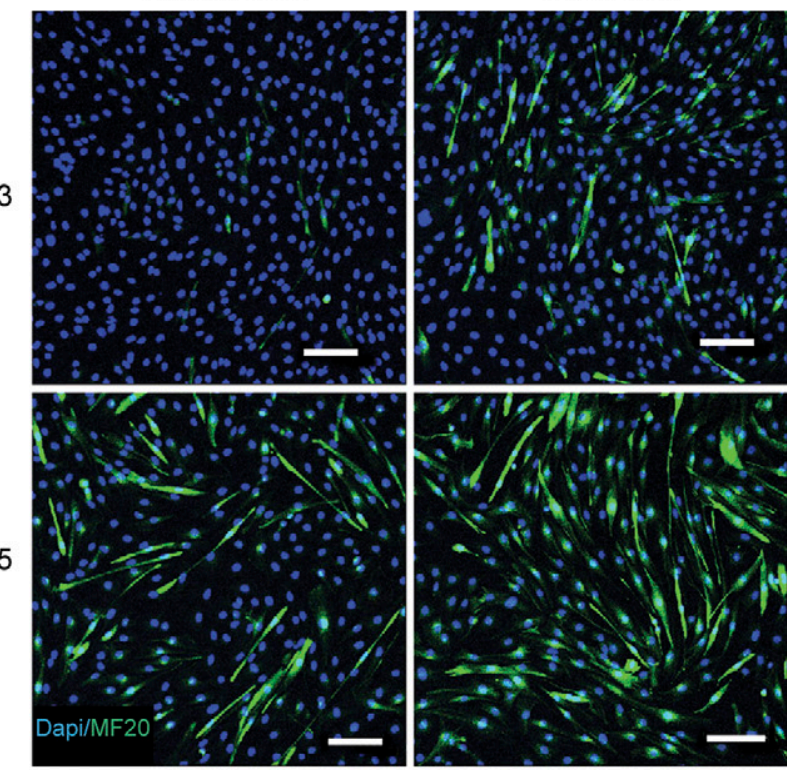

D

C2C12 differentation

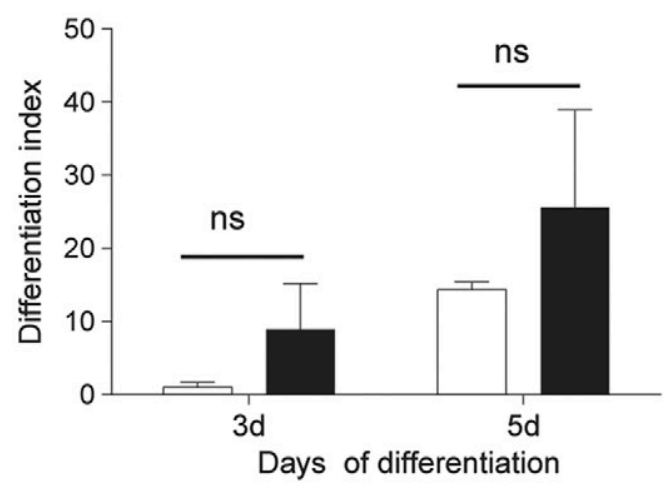

E

Mdx myoblast

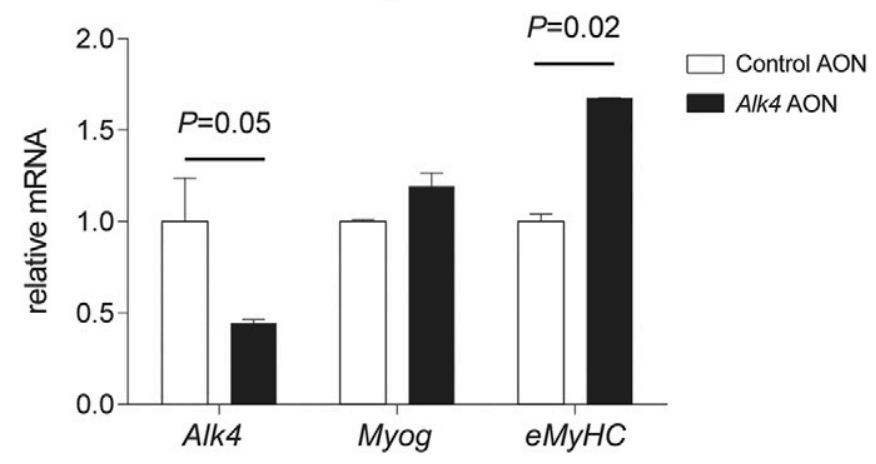

Figure 2. Alk4 AON blocks MSTN signaling and enhances myoblast differentiation. A) Alk4 AON (200 nM) specifically repressed MSTNinduced Smad3-dependent (CAGA) ${ }_{12}$-luciferase activity in C2C12 murine myoblasts, whereas Alk4 AON did not inhibit MSTN activity in C3H10T1/2 mesenchymal stem cells. LY364947 inhibitor (LY inh; $10 \mu \mathrm{M}$ ) was added to the cells as a positive control for blockage of MSTN activity. The cells were stimulated with MSTN or nonstimulated (NS). Firefly luciferase activity of (CAGA) ${ }_{12}$-luciferase constructs were normalized to Renilla luciferase activity of cotransfected CMV-renilla constructs. The normalized values are in relative light units (RLU). B) qPCR was performed to measure the Myog expression of C2C12 cells transfected with Alk4 or control AON (100 nM) at 3 and $5 \mathrm{~d}$ after initiation of myogenic differentiation. Alk4 AON increased the Myog expression. $C$ ) Immunofluorescence images of C2C12 cells transfected with Alk4 or control AON (100 nM) at 3 and $5 \mathrm{~d}$ after initiation of myogenic differentiation. Cells were stained with myosin (differentiated myotubes, green) and DAPI (nuclear, blue). Scale bars, $10 \mu \mathrm{m}$. D) The differentiation index was calculated as the percentage of the total number of myogenic cells that were myosin ${ }^{+}$. E) AON targeting exon 6 of Alk4 (Alk4 AON) and scrambled control AON were transfected at $50 \mathrm{nM}$ concentration into $m d x$ myoblasts. RNA was isolated after $48 \mathrm{~h}$. Real-time qPCR was performed to measure full-length Alk4 transcript down-regulation and myogenic gene expression. The data are presented as the average of the results of 3 independent experiments normalized to Gapdh and are shown relative to control AON samples. Error bars, SD. 
We also studied the effect of Alk4 AON-mediated exon skipping on $\mathrm{C} 2 \mathrm{C} 12$ myoblast differentiation. $\mathrm{C} 2 \mathrm{C} 12$ cells were transfected with Alk4 AON and $4 \mathrm{~h}$ later, differentiation was induced by serum starvation. At d 3, C2C12 cells were transfected again with $A l k 4 \mathrm{AON}$, and differentiation was monitored for up to $5 \mathrm{~d}$. Expression of myogenin $(\mathrm{Myog})$ was increased in Alk4 AON-transfected C2C12 cells (Fig. 2B). Alk4 AON-transfected cells also showed an increased number of $\mathrm{MHC}^{+}$cells (marker for myotubes) normalized to the total number of $\mathrm{DAPI}^{+}$cells (marker for nuclei) (Figs. 2C, D). Comparable down-regulation on the transcript level and an increase in myogenic gene expression was also detected in primary myoblasts isolated from $m d x$ EDL muscles (Fig. 2E). In summary, partial blockage of ALK4 with AON-mediated exon skipping enhanced myoblast differentiation in vitro.

\section{Efficient Alk4 exon skipping decreases muscle mass but has no effect on tibialis anterior muscle contraction physiology in $\mathrm{mdx}$ mice}

Next, we evaluated whether Alk4 exon skipping has a positive effect on muscle regeneration in vivo in the $m d x$ mouse model, using ViMs, as they are more efficient in vivo. We first assessed whether our Alk4 ViM exerted effects comparable to those of the Alk4 AON in vitro. In $\mathrm{C} 2 \mathrm{C} 12$ cells, Alk4 ViM led to an efficient, dose-dependent $(1,2,5$, and $10 \mu \mathrm{M}$ naked uptake) exon 6 skipping and a significant 85\% decrease in Alk4 transcript levels (Fig. 3A). Similar to the results obtained with Alk4 AON, Alk4 ViM significantly increased Myog gene expression and did not affect $A l k 5$ transcript expression in C2C12 cells. $M d x$ mice were intramuscularly injected with Alk4 ViM or standard control ViM (nontargeting) in the gastrocnemius and/or tibialis anterior muscles on 2 consecutive days and euthanized $1 \mathrm{wk}$ (short-term treatment) or $7 \mathrm{wk}$ (long-term treatment) after the first injection. In the long-term treatment, a third injection was given $4 \mathrm{wk}$ after the first. It appeared that $25 \%$ exon skipping and 30\% downregulation were achieved in the gastrocnemius muscles (Fig. 3B). Comparable Alk4 down-regulation took place in the tibialis anterior muscles. We achieved a specific Alk4 down-regulation as Alk5 and Alk7 transcripts remained unaffected in gastrocnemius muscles after long-term treatment. Unexpectedly, the gastrocnemius muscle mass had significantly decreased by $10 \%$ after long-term Alk4 ViM treatment. Moreover, the tibialis anterior muscle mass had significantly decreased (by 20\%) after long-term Alk4 ViM treatment (Fig. 3C).

To investigate whether the significant decrease in muscle mass after long-term Alk4 ViM treatment affected muscle function, we performed tibialis anterior physiology analysis with a focus on the force-frequency relationship and resistance to eccentric contractions. The force-frequency curve of fast-twitch tibialis anterior muscles stayed flat at low frequencies and rose rapidly from $50 \mathrm{~Hz}$ onward (Fig. 3D). In relation to type of treatment, we found that tibialis anterior muscles treated with Alk4 ViM did not generate a lower specific force than in control ViM-treated muscles over a wide range of stimulation intensities $(10-180 \mathrm{~Hz})$. We also measured the tibialis anterior muscle's response to eccentric contraction, which can induce injury in $m d x$ muscle fibers (32). Tibialis anterior muscles were repetitively stimulated at $120 \mathrm{~Hz}$ and stretched to $110 \%$ of their resting length. The isometric force dropped by $10 \%$ in $m d x$ mice (Fig. $3 E$ ). There were no significant differences in this respect between control and Alk4 ViM-treated muscles. Taken together, our results suggest that long-term Alk4 down-regulation exerts no effect on muscle force and contraction of individual muscle fibers.

\section{Induction of muscle regeneration in mox muscles after long-term Alk4 down-regulation}

In search for the mechanisms behind this unexpected lowering of the muscle mass and considering that regenerative fibers are smaller, we looked at induction of muscle de- and regeneration after Alk4 exon skipping. The latter would be in line with the observed increase in myoblast differentiation after in vitro Alk4 AON transfection. The effect of Alk4 transcript down-regulation on muscle regeneration in $m d x$ mice was examined by looking at $e M y H C$ expression on RNA and protein level. The $\mathrm{eMyHC}^{+}$area significantly increased in gastrocnemius muscle after long-term Alk4 ViM treatment (1.5 vs. 0.5\% surface area for Alk4 and control ViM-treated muscles, respectively) (Fig. $4 A, B$ ). Moreover, an increase in muscle regeneration was confirmed by qPCR analysis measuring the myogenic gene expression (eMyHC and Myog) in Alk4 ViM gastrocnemius muscles (Fig. 4C). We measured the effect of Alk4 ViM treatment on fiber size distribution as regenerative fibers are smaller in size. To demonstrate whether the switch toward smaller fiber sizes for Alk4 ViM treatment was significant, we applied logistic regression. This analysis revealed that the number of smaller fibers (50-1000 $\mu \mathrm{m}^{2}$ ) in Alk4 ViM-treated gastrocnemius muscles had significantly increased, whereas the number of larger fibers (1001-5000 $\mathrm{\mu m}^{2}$ ) had significantly decreased $(P<0.001 ;$ Fig. $4 D)$. The mean fiber area decreased significantly $(P=0.0024)$ after Alk4 ViM treatment (Fig. 4E).

\section{Alk4 exon skipping has no effect on fibrosis and fiber-type composition in $\mathbf{m d x}$ muscles}

To investigate the effect of Alk4 knockdown on muscle quality, we measured the fibrotic area in gastrocnemius muscles treated with Alk4 or with control ViM (Supplemental Fig. S1 $A$ ). The size of the fibrotic areas did not differ significantly between the 2 treatments, nor did the expression levels of genes involved in fibrosis: collagen type I $\alpha 1$ Col1a1), plasminogen activator inhibitor type 1 (Pai-1), and connective tissue growth factor (Ctgf) (Supplemental Fig. S1B). This finding implies that Alk4 down-regulation does not affect gene regulation for fibrotic genes in dystrophic muscles. To study whether the decrease in muscle mass after Alk4 ViM treatment could have been the result of altered fiber-type composition, we compared the relative gene expression levels of the MyHC isoforms IIx, IIa, 

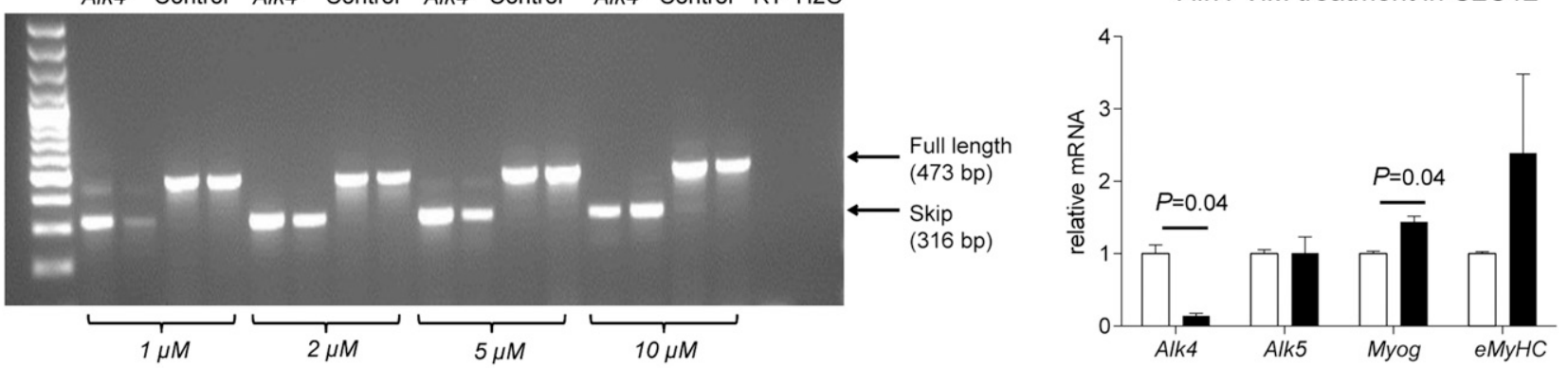

B

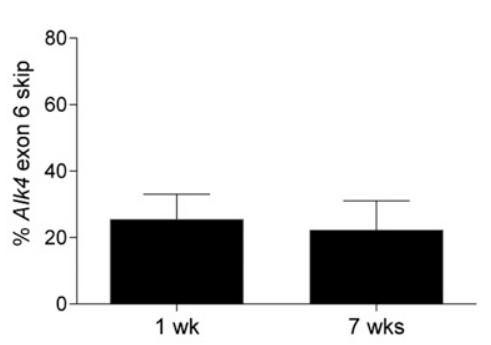

Gastro

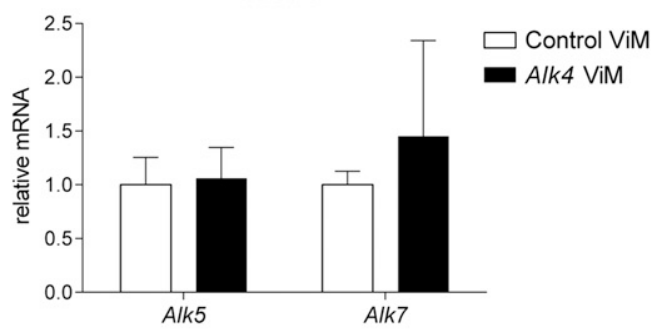

D

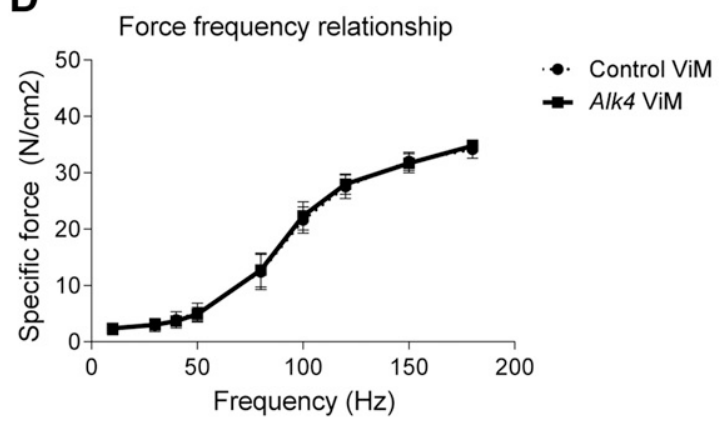

Gastro

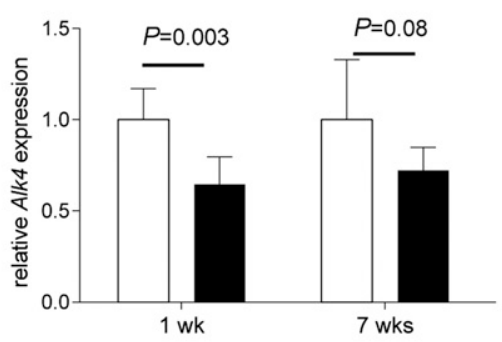

C

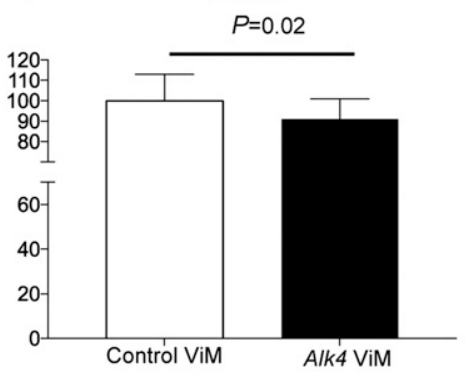

TA

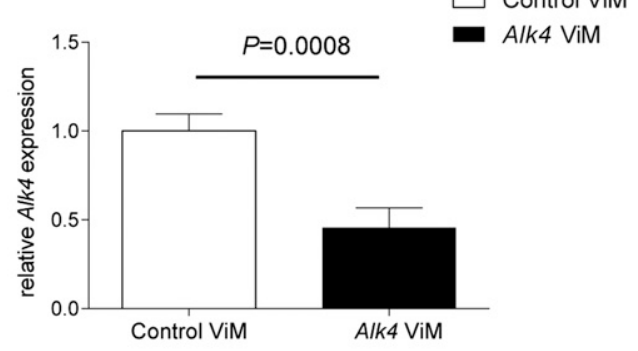

E
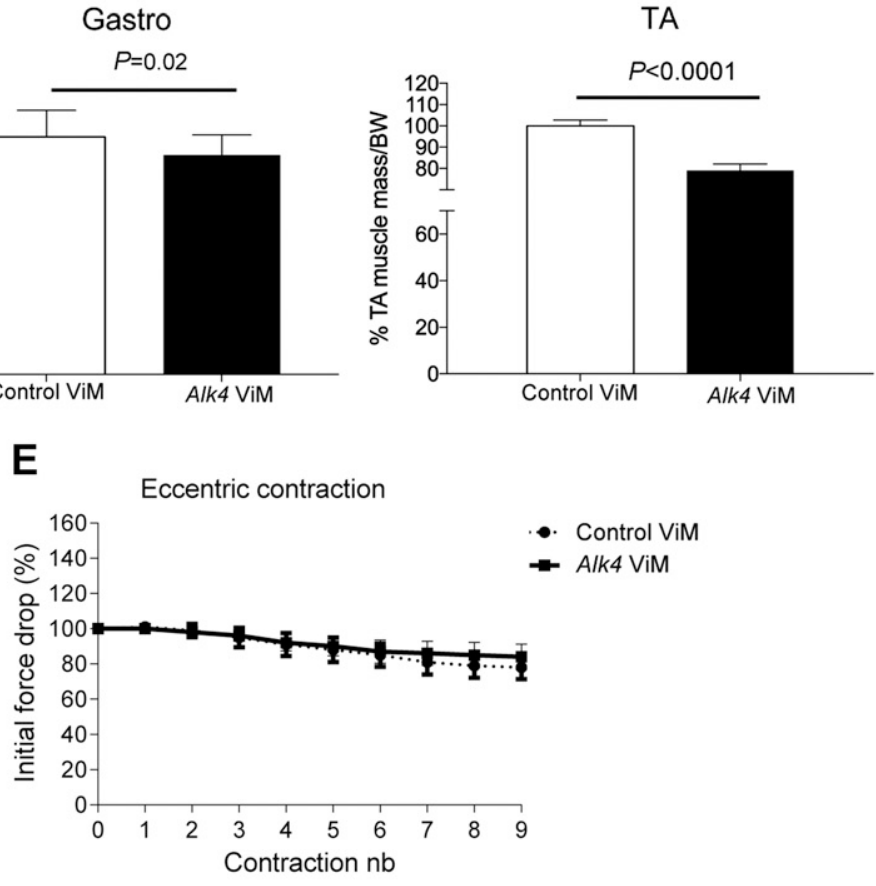

Figure 3. Effect of Alk4 down-regulation with ViM in C2C12 cells, $m d x$ gastrocnemius and tibialis anterior muscles. A) ViM targeting exon 6 of Alk4 was added to cells without any transfection reagent at $1-10 \mu \mathrm{M}$ for $72 \mathrm{~h}$, and exon skip efficiency was measured with RT-PCR. Alk4 and Alk5 transcripts and myogenic gene expression were measured with qPCR of samples treated with $1 \mu \mathrm{M} A l k 4$ and control ViM. B) Percentages of exon skipping of Alk4 or control ViM-injected gastrocnemius muscles after 1 and 7 wk of treatment were measured. qPCR was performed to measure Alk4 full-length transcript of Alk4 or control ViM-injected gastrocnemius and tibialis anterior muscles. Specific Alk4 transcript down-regulation was measured in gastrocnemius muscles after $1(n=6)$ and 7 $(n=6)$ wk of treatment and in tibialis anterior muscles after $7 \mathrm{wk}(n=4)$ of treatment. qPCR was performed to measure Alk5 and Alk 7 transcripts of long-term Alk4 or control ViM-injected gastrocnemius muscles. No differences in either transcript were detected after the treatment. C) Weighing of the Alk4 ViM-treated gastrocnemius muscles showed a $10 \%$ decrease, and tibialis anterior muscles showed a $20 \%$ decrease relative to control ViM. Muscle weights were normalized to the body weights at the endpoint of the experiment. $D$ ) Force $v s$. frequency for the tibialis anterior muscles treated intramuscularly with Alk4 ViM and contralaterally with control ViM for $7 \mathrm{wk}(n=6)$. Each data point represents the force measured at each frequency. No significant differences in the total force were measured between control and Alk4 ViM-treated muscles. E) Relative changes in tetanic force during 9 cycles of eccentric contraction in tibialis anterior muscles $(n=6)$ treated intramuscularly with Alk4 ViM and in contralateral muscles treated with control ViM for $7 \mathrm{wk}$. The tetanic tension developed during the second cycle was taken as $100 \%$. No significant differences in the initial force decrease between control and Alk4 ViM-treated muscles were measured. Error bars, SD $(A-C)$ and SEM $(D, E)$. 

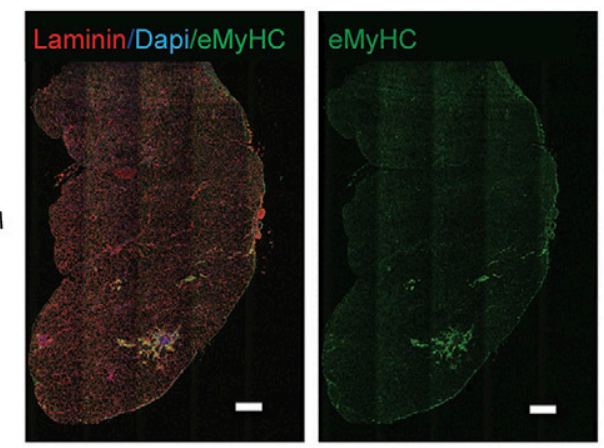

B

Control ViM
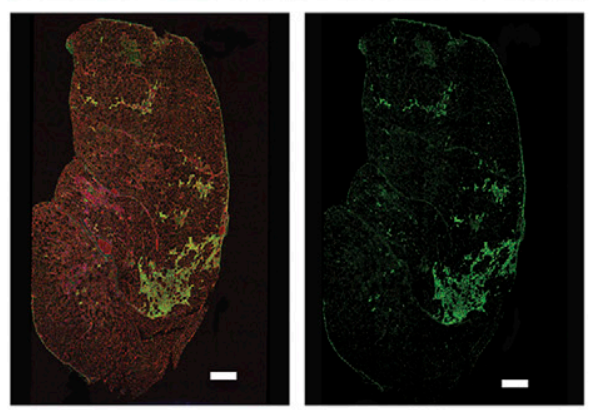

C eMyHC
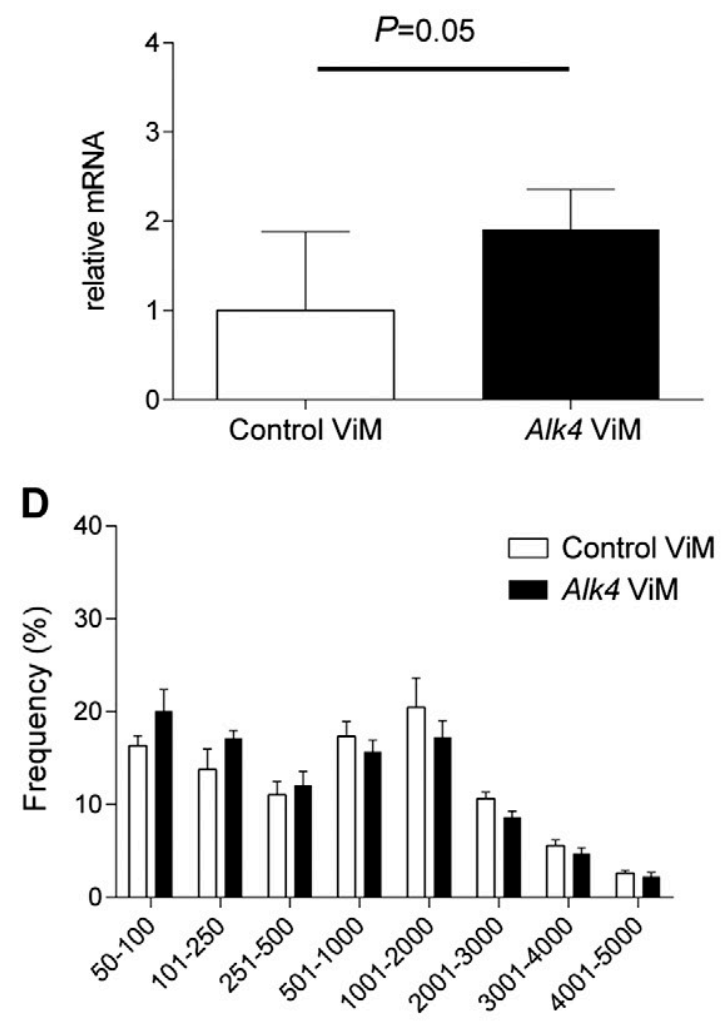

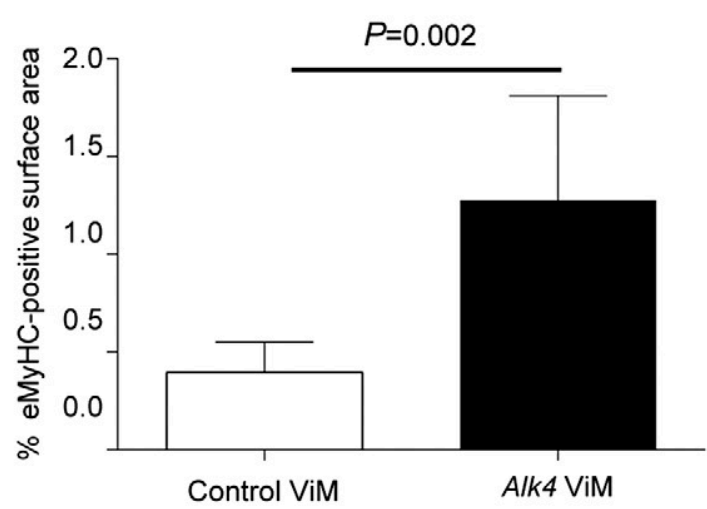

Myog

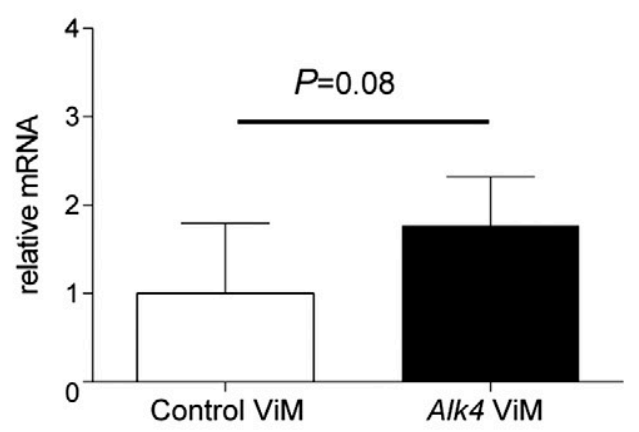

E

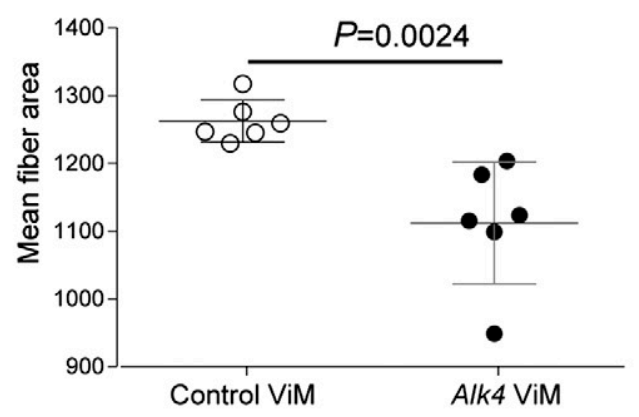

Fibers size $(\mu \mathrm{m} 2)$

Figure 4. Alk4 down-regulation increases muscle regeneration in $m d x$ gastrocnemius muscles. A) Immunofluorescence images of $m d x$ gastrocnemius muscles treated with $A l k 4$ and control ViM for $7 \mathrm{wk}$ and stained with eMyHC (regenerative fibers, green), laminin (extracellular matrix of muscle fibers, red) and DAPI (nuclear, blue). Scale bars, $100 \mu \mathrm{m}$. B) A significant increase in eMyHC-positive area was found in muscles treated with Alk4 ViM. C) Myogenic gene expression measured by qPCR, normalized to $\operatorname{Gapdh}(n=6)$. Up-regulation of myogenic gene expression ( $M y g$ and $e M y H C$ ) was found after 7 wk of $A l k 4$ ViM intramuscular injections. D) The minimal fiber area was set at $50 \mu \mathrm{m}^{2}$ and the maximum fiber area at $10,000 \mu \mathrm{m}^{2}$. Between 7 and 10 microscopic views were counted and analyzed, resulting in an average total number of 5000-7500 fibers per muscle. Alk4 ViMtreated muscles showed a significantly higher number of smaller fibers $\left(50-1000 \mu \mathrm{m}^{2}\right)$ and a significantly lower number of larger fibers $\left(1001-5000 \mathrm{~mm}^{2}\right)$ than control ViM-treated muscles. E) The mean fiber area was significantly decreased after treatment with Alk4 ViM in muscles. Error bars, SD. 
and IIb measured by qPCR and performed immunofluorescence staining. The relative gene expression levels of $\mathrm{MyHC}$ isoforms IIx, IIa, and IIb (Supplemental Fig. S1C) and immunofluorescence analysis of type IIa and IIb fibers (Supplemental Fig. S1D, E) did not differ significantly between muscles treated with Alk4 and control ViM.

\section{Effect of Alk4 exon skipping in adult WT mice}

To study whether the Alk4-knockdown-mediated decrease in muscle mass was developmentally regulated or induced by the dystrophic phenotype of the $m d x$ mice, we injected Alk4 ViM intramuscularly in adult WT mice and performed the same analyses as described for $m d x$ mice. A significant $60 \%$ Alk 4 exon skipping and $70 \%$ transcript down-regulation was achieved in gastrocnemius muscles and comparable transcript down-regulation in tibialis anterior muscles (Fig. $5 A$ ). Similar to $m d x$ gastrocnemius muscles, the achieved Alk4 down-regulation was specific, without affecting the expression of Alk5 and Alk7 transcripts (Fig. 5B). Surprisingly, we found an even more pronounced drop in muscle mass in adult WT mice (15\% muscle mass drop in gastrocnemius and 30\% in tibialis anterior muscles; Fig. 5C).

As with $m d x$ mice, the long-term Alk4 down-regulation and a significant muscle mass decrease did not show any
A

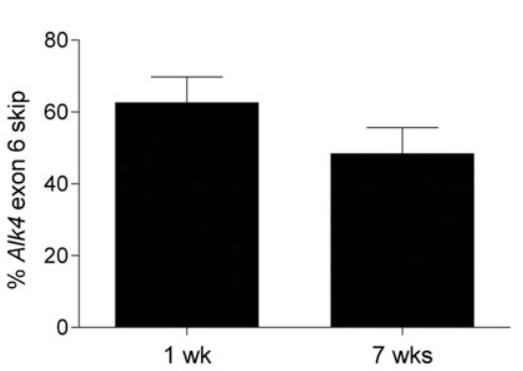

B

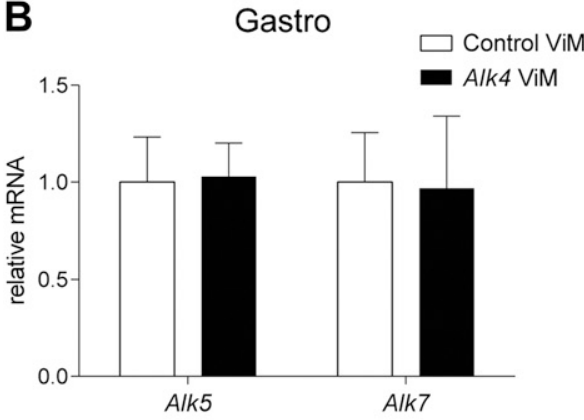

D Force frequency relationship

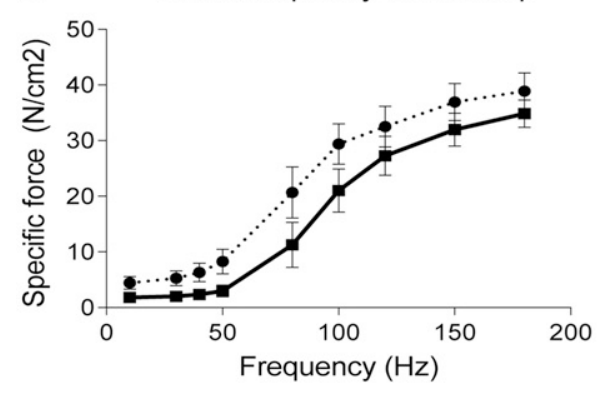

Gastro

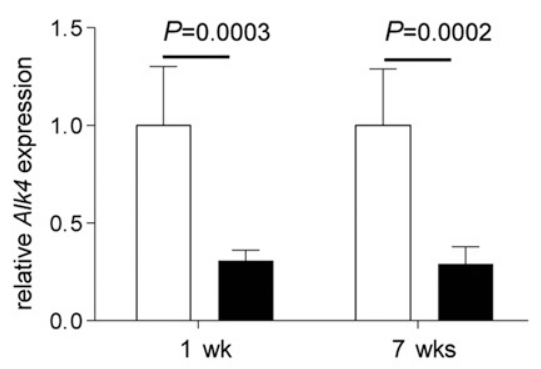

C
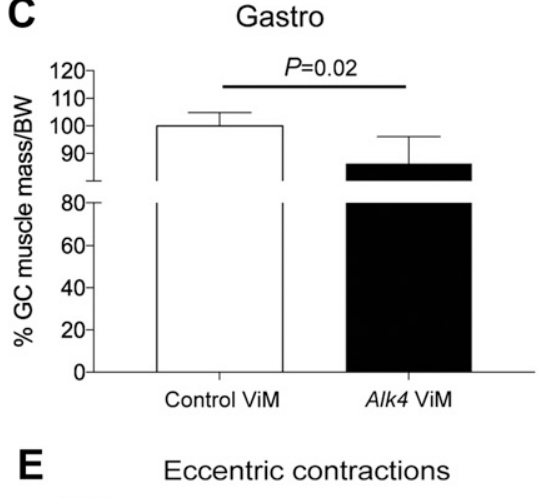

E Eccentric contractions

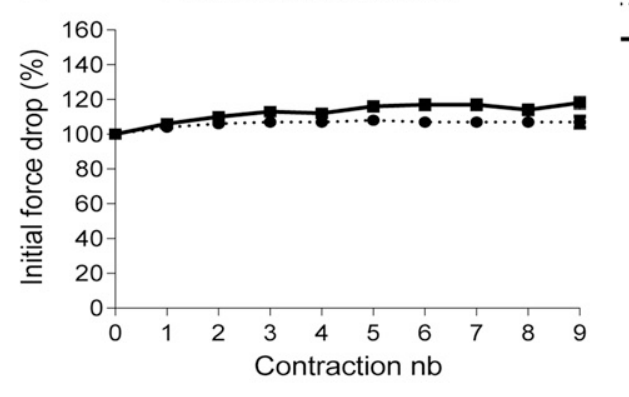

TA
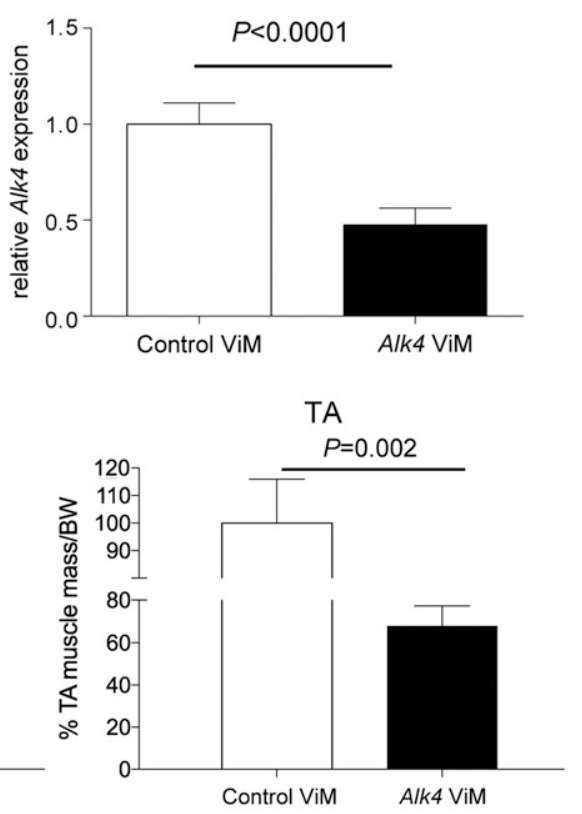

-. Control ViM

- Alk4 ViM

Figure 5. Alk4 exon skipping decreases gastrocnemius muscle mass but has no effect on muscle physiology in WT mice. A) Percentages of exon skipping of Alk4 or control ViM-injected gastrocnemius muscles after 1 and 7 wk of treatment were measured. Specific Alk4 transcript down-regulation in gastrocnemius $(n=6)$ and tibialis anterior $(n=4)$ muscles was measured. $B$ ) qPCR was performed to measure Alk5 and Alk7 transcripts of long-term Alk4 or control ViM-injected gastrocnemius muscles. No differences were detected after the treatment in either transcript. C) Weighing of the Alk4 ViM-treated gastrocnemius muscles showed a $25 \%$ decrease and tibialis anterior muscles showed a $30 \%$ decrease in mice relative to control ViM. Muscle weights were normalized to the body weights at the endpoint of the experiment. $D$ ) Force vs. frequency for the tibialis anterior muscles of treated intramuscularly with Alk4 ViM and contralaterally with control ViM for 7 wk $(n=8)$. Each data point represents the force measured at each frequency. No significant differences in the total force were measured between control and Alk4 ViMtreated muscles. $E$ ) Relative changes in tetanic force during 9 cycles of eccentric contraction in tibialis anterior muscles $(n=8)$ treated intramuscularly with Alk4 ViM and contralaterally with control ViM for $7 \mathrm{wk}$. The tetanic tension developed during the second cycle was taken as $100 \%$. No significant differences in the initial force drop between control and Alk4 ViM-treated muscles were measured. Error bars, SD $(A-C)$ and SEM $(D, E)$. 
effect on muscle force and contraction in adult WT mice (Fig. 5D,E). We also studied the effect of Alk4 transcript down-regulation on muscle regeneration. A significant increase in muscle regeneration was detected by qPCR analysis measuring the myogenic gene expression (eMyHC and Myog) in Alk4 ViM gastrocnemius muscles (Fig. 6A). Comparable eMyHC and Myog gene upregulation was found in tibialis anterior muscles. The regenerative area was not measured, because only a few $\mathrm{eMyHC}^{+}$fibers were detectable by immunohistochemistry. In addition, we looked at the effect on fiber size distribution and we found that the number of smaller fibers $\left(50-1000 \mu \mathrm{m}^{2}\right)$ in Alk4 ViM-treated gastrocnemius muscles had significantly increased, whereas the number of larger fibers $\left(1001-5000 \mu \mathrm{m}^{2}\right)$ had significantly decreased $(P=$ $0.026)$ (Fig. 6B), but the mean fiber area remained unchanged (Fig. 6C).

We also measured the fibrotic area in WT gastrocnemius muscles treated with Alk4 or with control ViM. As seen in $m d x$ mice, the size of the fibrotic areas did not significantly differ between the 2 treatments, nor did the expression levels of genes involved in fibrotic gastrocnemius muscles (Supplemental Fig. S2A, B). Last, we studied the effect of Alk4 ViM treatment on fiber type composition. In Alk4 ViM-treated muscles the levels of the Myh1 (MyHC IIx) and Myh2 (MyHC IIa) isoforms had significantly increased relative to control ViM-treated muscles (Fig. 6D); however, no significant changes were found for Myh7 (MyHC I) and Myh4 (MyHC IIb) levels (data not shown). Immunohistochemistry showed a slight, nonsignificant increase in type IIa fibers and no difference in type $\mathrm{Ilb}$ fibers in Alk4 ViM-treated muscles (Supplemental Fig.S2C, $D$ ). This finding indicates that Alk4 knockdown in muscles led to an increase in oxidative endurance fibers, but no reduction in fast-twitch glycolytic fibers. This result was further supported by the finding that mRNA levels of $P d k 4$, an inhibitor of pyruvate dehydrogenase and an activator of oxidative metabolism (33), was significantly upregulated after long-term Alk4 ViM treatment (Fig. 6E). We thus expected an increase in $\beta$ oxidation in response to Alk4 down-regulation and indeed found a significant upregulation of carnitine palmitoyltransferase $1 b(C p t 1 b)$ mRNA levels in long-term-treated muscles. In addition, we found a significant increase in Porin mRNA transcript (Fig. 6F), which is a marker for mitochondrial function (34).

\section{Alk4 down-regulation induces muscle atrophy via ATF4 in WT mice}

To obtain an unbiased view of the genes and molecular pathways affected in response to Alk4 down-regulation, we decided to perform RNAseq. Samples from WT gastrocnemius muscles subjected to long-term treatment with Alk4 ViM $(n=6)$ or control ViM $(n=6)$ were sequenced using the Illumina sequencing platform, given that the drop in muscle mass was most pronounced. After cleaning and quality evaluation, each sample contained $\sim 20$ million useful reads. The reads were aligned to the Mus musculus mm 10 genome sequence; $>95 \%$ of transcripts were mapped uniquely. Differentially expressed gene analysis was performed on 10,541 genes using $3 \mathrm{R}$
Bioconductor packages: DESeq2 (35), limma-voom (36) and edgeR (37). Read counts for all samples were well normalized (Supplemental Fig. S3A). All 3 packages reported $\sim 1000$ differentially expressed genes upon Alk4 ViM treatment (Supplemental Fig. S3B), with Alk4 being the most significant down-regulated gene (dot corresponding to Alk4 indicated by an asterisk in Supplemental Fig. S3C). The expression analyses revealed 560 genes to be up-regulated and 310 to be down-regulated consistently in all 3 analyses (Supplemental Fig. S3C). To identify biologic pathways and networks affected in response to Alk4 down-regulation, KEGG pathway gene sets were tested for associations using the $\mathrm{R}$ Bioconductor global test package (23) (Table 2). The metabolic pathways leading to muscle starvation and amino acid deprivation appeared to be the most affected pathways in response to Alk4 downregulation. In addition, the folding, sorting, and degradation pathway was activated, which is also known as unfolded protein response (UPR) or endoplasmic reticulum stress. Using the OncoFinder biomathematical method $(25,26)$, we were able to distinguish the activator and repressor role of every gene in each pathway of the gene expression data for individual samples (Table 3). Similar to KEGG findings, protein degradation pathways were activated by Alk4 down-regulation, whereas protein and glucose synthesis were inhibited leading to muscle wasting. Furthermore, the cluster of differentiation (CD) 40 pathway was highly activated, which is known to induce a proinflammatory response via tumor necrosis factor receptor-associated factors (TRAF2 and -3) (38). Further, pathways known to induce inflammation, such as IL2 and TNF- $\alpha$ signaling pathways (39), were activated in response to treatment.

The RNAseq analysis revealed that pathways involved in protein degradation were activated in response to Alk4 down-regulation in WT muscles. One of the key regulators of protein degradation is muscle RING-finger protein-1 (MuRF-1/Trim63), which activates protein degradation via the ubiquitin proteasome $(40,41)$. Murf-1 was highly up-regulated in response to Alk4 down-regulation in our RNAseq data. We validated differences in Murf-1 gene expression with qPCR. Murf-1 gene expression was significantly up-regulated in response to Alk4 down-regulation (Fig. 7A).

With the Upstream Regulator Analysis algorithm of IPA, we identified activating transcription factor-4 (Atf4) as 1 of the most significant upstream targets $\left(P=9.13 \mathrm{E}^{-26}\right)$. Atf4 is a regulator of genes involved in muscle atrophy, such as growth arrest and DNA-damage inducible $\alpha$ (Gadd45a), cyclin-dependent kinase inhibitor 1a (Cdkn1a), and ankyrin repeat domain 1 (Ankrd1) (42, 43). Atf4, $C d k n 1 a$, Gadd $45 a$, and Ankrd1 genes were significantly upregulated in the RNA-seq data after long-term treatment with Alk4 ViM. qPCR analysis confirmed a significant increase in Atf4, Cdkn1a, and Gadd45a in these samples (Fig. $7 A$ ). This effect was also detected after 1 wk of treatment, suggesting a very fast activation of the atrophic response.

The KEGG and OncoFinder-based pathway analyses showed that the most affected pathways in response to Alk4 down-regulation were metabolic pathways resulting from muscle starvation and amino acid deprivation. One 
A

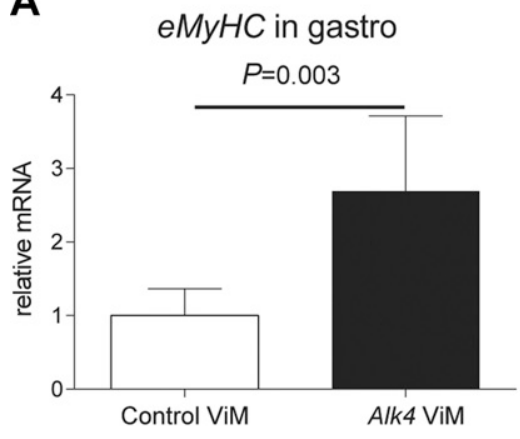

Myog in gastro

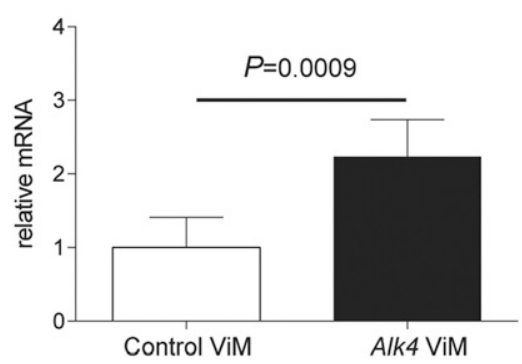

eMyHC in TA

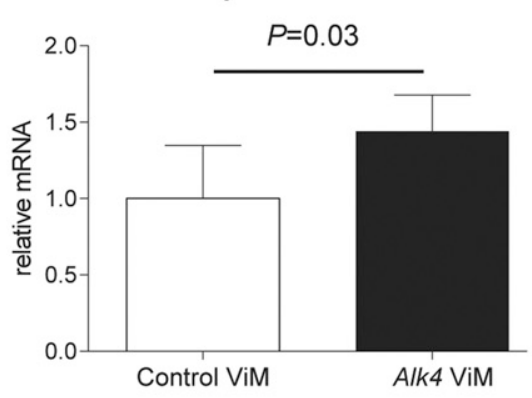

Myog in TA

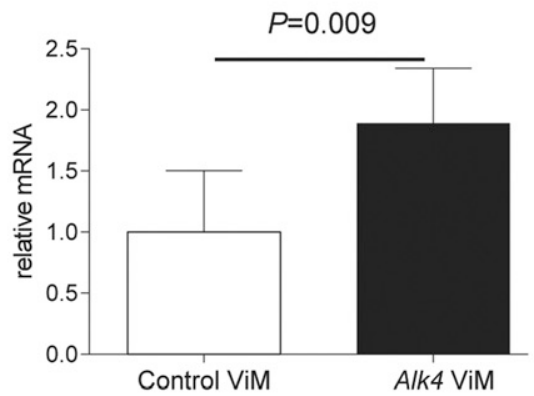

B

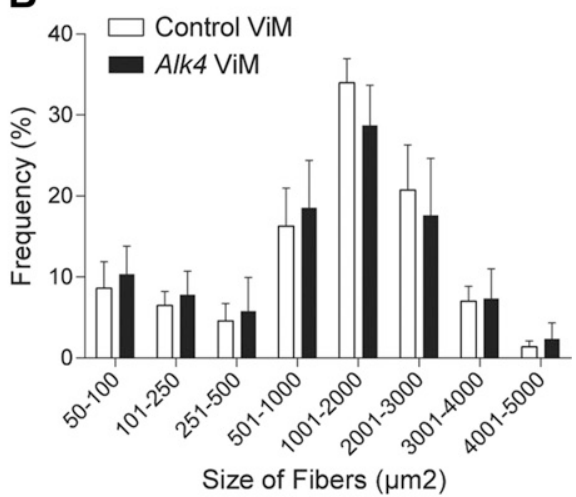

C

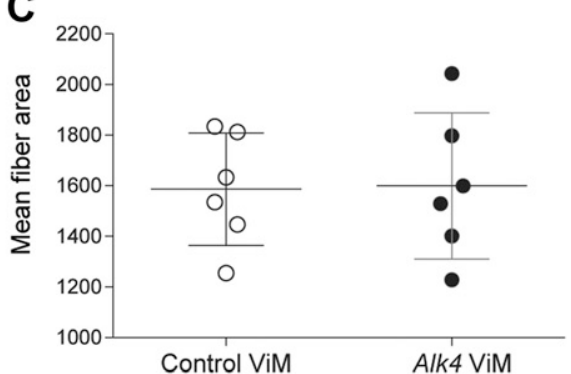

D Myh1 (type Ilx)

Myh2 (type IIA)
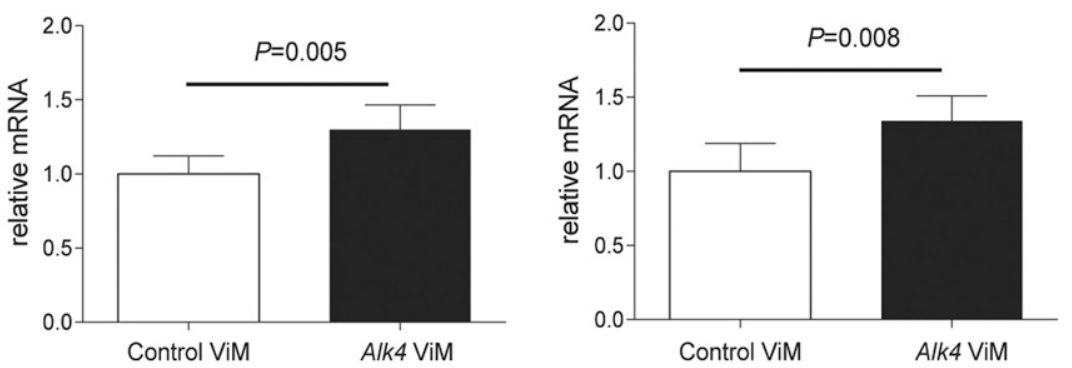

E Pdk4

Cpt1b
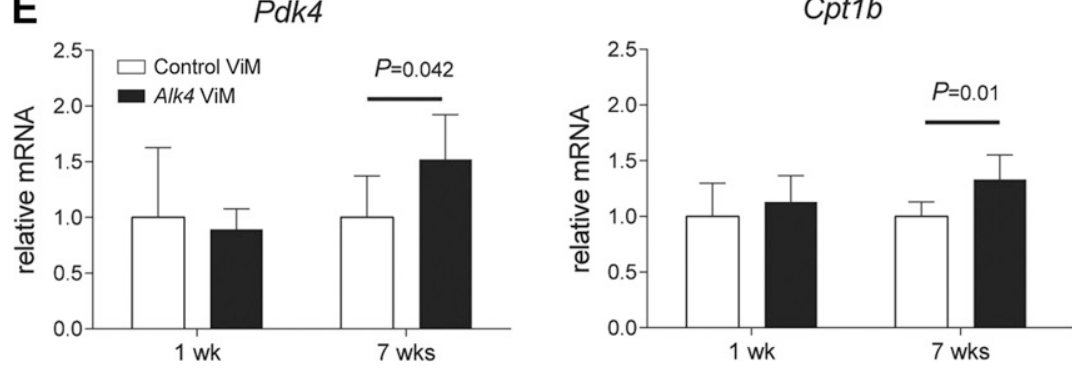

F

Porin

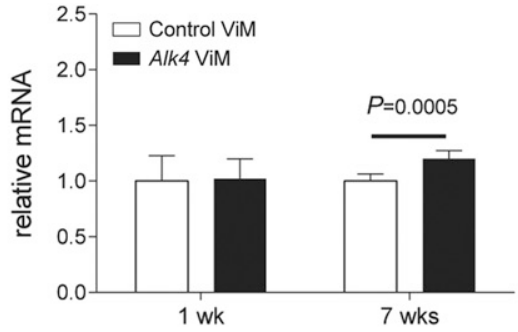

Figure 6. Alk4 down-regulation induces muscle regeneration and fiber-type switch toward oxidative endurance fibers in WT gastrocnemius muscles. A) Myogenic gene expression was measured by qPCR. Significant up-regulation of $e M y H C$ and $M y o g$ was found after $7 \mathrm{wk}$ of Alk4 ViM intramuscular treatment in gastrocnemius and tibialis anterior muscles. B) Alk4 ViM-treated gastrocnemius showed a significantly higher number of smaller fibers $\left(50-1000 \mu \mathrm{m}^{2}\right)$ and a significantly lower number of larger fibers (1001-5000 $\mathrm{mm}^{2}$ ) than control ViM-treated muscles. C) The mean fiber area was not significantly changed after treatment with Alk4 ViM. D) A significant up-regulation of $M y H C$ IIx and IIa isoforms was found in Alk4 ViM-treated muscles. E) Gene expression of Pdk4 and Cpt1b was significantly increased after $7 \mathrm{wk}$ of Alk4 ViM treatment. F) The gene expression of Porin was significantly increased at $7 \mathrm{wk}$ in Alk4 ViM-treated muscles. Gene expression levels were normalized to Gapdh and are depicted relative to control-treated muscles. Error bars, SD.

of the markers of low glucose level, asparagine synthetase (Asns), was highly up-regulated in response to Alk4 down-regulation. A significant increase in Asns gene expression was confirmed by qPCR analysis in gastrocnemius muscles after 1 and 7 wk of Alk4 ViM treatment (Fig. 7B). In addition to the metabolic changes, both
KEGG-based pathway analysis and IPA showed a significant up-regulation of UPR after Alk4 down-regulation. A significant increase in DNA damage inducible transcript 3 (Ddit3, or Chop) gene expression (a marker of UPR that is activated via Atf4) after $7 \mathrm{wk}$ of Alk4 ViM treatment was confirmed with qPCR analysis (Fig. 7C). 
TABLE 2. Biologic pathways affected significantly in response to Alk4 down-regulation using KEGG-based analysis

\begin{tabular}{|c|c|c|}
\hline Description & Class & $P$ \\
\hline Alanine, aspartate and glutamate metabolism & Amino acid metabolism & $1.86 \mathrm{E}^{-08}$ \\
\hline Vitamin B6 metabolism & Metabolism of cofactors and vitamins & $2.22 \mathrm{E}^{-08}$ \\
\hline Glycine, serine and threonine metabolism & Amino acid metabolism & $1.15 \mathrm{E}^{-07}$ \\
\hline Nitrogen metabolism & Energy metabolism & $1.28 \mathrm{E}^{-07}$ \\
\hline Amino sugar and nucleotide sugar metabolism & Carbohydrate metabolism & $1.75 \mathrm{E}^{-07}$ \\
\hline p53 signaling pathway & Cell growth and death & $6.68 \mathrm{E}^{-07}$ \\
\hline Metabolic pathways & Metabolic pathways & $9.52 \mathrm{E}^{-07}$ \\
\hline One carbon pool by folate & Metabolism of cofactors and vitamins & $1.10 \mathrm{E}^{-06}$ \\
\hline Lysosome & Transport and catabolism & $1.31 \mathrm{E}^{-06}$ \\
\hline Aminoacyl-tRNA biosynthesis & Translation & $1.33 \mathrm{E}^{-06}$ \\
\hline NOD-like receptor signaling pathway & Immune system & $1.85 \mathrm{E}^{-06}$ \\
\hline$\alpha$-Linolenic acid metabolism & Lipid metabolism & $2.02 \mathrm{E}^{-06}$ \\
\hline Starch and sucrose metabolism & Carbohydrate metabolism & $2.14 \mathrm{E}^{-06}$ \\
\hline Long-term depression & Nervous system & $2.68 \mathrm{E}^{-06}$ \\
\hline RNA transport & Translation & $3.04 \mathrm{E}^{-06}$ \\
\hline Glycerophospholipid metabolism & Lipid metabolism & $6.04 \mathrm{E}^{-06}$ \\
\hline Arginine and proline metabolism & Amino acid metabolism & $8.57 \mathrm{E}^{-06}$ \\
\hline Biosynthesis of unsaturated fatty acids & Lipid metabolism & $8.73 \mathrm{E}^{-06}$ \\
\hline Protein processing in endoplasmic reticulum & Folding, sorting and degradation & $8.95 \mathrm{E}^{-06}$ \\
\hline Glycosaminoglycan biosynthesis-heparan sulfate & Glycan biosynthesis and metabolism & $9.04 \mathrm{E}^{-06}$ \\
\hline Valine, leucine and isoleucine biosynthesis & Amino acid metabolism & $9.66 \mathrm{E}^{-06}$ \\
\hline TGF- $\beta$ signaling pathway & Signal transduction & $9.97 \mathrm{E}^{-06}$ \\
\hline Fat digestion and absorption & Digestive system & $1.51 \mathrm{E}^{-05}$ \\
\hline Phagosome & Transport and catabolism & $1.66 \mathrm{E}^{-05}$ \\
\hline Bile secretion & Digestive system & $1.92 \mathrm{E}^{-05}$ \\
\hline Gap junction & Cellular community & $2.08 \mathrm{E}^{-05}$ \\
\hline Proximal tubule bicarbonate reclamation & Excretory system & $2.11 \mathrm{E}^{-05}$ \\
\hline Carbohydrate digestion and absorption & Digestive system & $2.57 \mathrm{E}^{-05}$ \\
\hline Histidine metabolism & Amino acid metabolism & $2.64 \mathrm{E}^{-05}$ \\
\hline Alzheimer's disease & Neurodegenerative diseases & $2.66 \mathrm{E}^{-05}$ \\
\hline Gastric acid secretion & Digestive system & $2.70 \mathrm{E}^{-05}$ \\
\hline Amyotrophic lateral sclerosis (ALS) & Neurodegenerative diseases & $3.53 \mathrm{E}^{-05}$ \\
\hline Protein export & Folding, sorting and degradation & $4.04 \mathrm{E}^{-05}$ \\
\hline ErbB signaling pathway & Signal transduction & $4.13 \mathrm{E}^{-05}$ \\
\hline mTOR signaling pathway & Signal transduction & $4.54 \mathrm{E}^{-05}$ \\
\hline Glutathione metabolism & Metabolism of other amino acids & $5.24 \mathrm{E}^{-05}$ \\
\hline Aldosterone-regulated sodium reabsorption & Excretory system & $6.55 \mathrm{E}^{-05}$ \\
\hline Cell cycle & Cell growth and death & $8.52 \mathrm{E}^{-05}$ \\
\hline Oxidative phosphorylation & Energy metabolism & $8.62 \mathrm{E}^{-05}$ \\
\hline Basal transcription factors & Transcription & $1.01 \mathrm{E}^{-04}$ \\
\hline RNA degradation & Folding, sorting and degradation & $1.15 \mathrm{E}^{-04}$ \\
\hline Glycolysis/gluconeogenesis & Carbohydrate metabolism & $1.16 \mathrm{E}^{-04}$ \\
\hline Proteasome & Folding, sorting and degradation & $1.48 \mathrm{E}^{-04}$ \\
\hline Adipocytokine signaling pathway & Endocrine system & $1.49 \mathrm{E}^{-04}$ \\
\hline Pancreatic secretion & Digestive system & $1.59 \mathrm{E}^{-04}$ \\
\hline Hepatitis C & Infectious diseases & $1.67 \mathrm{E}^{-04}$ \\
\hline Acute myeloid leukemia & Cancers & $1.99 \mathrm{E}^{-04}$ \\
\hline Parkinson's disease & Neurodegenerative diseases & $2.13 \mathrm{E}^{-04}$ \\
\hline
\end{tabular}

NOD, nucleotide-binding and oligomerization domain, leucine-rich repeat.

The OncoFinder method revealed that the CD40, TNF- $\alpha$, and IL2 signaling pathways were activated in response to Alk4 down-regulation. These pathways activate a proinflammatory response and thereby increase the expression of inflammatory cytokines $(38,39)$. We measured the expression of CD68 (Cd68) and lectin galactosidase-binding soluble 3 (Lgals3) (inflammatory markers) with qPCR and found a significant increase in Alk4 ViM-treated muscles (Fig. 7D).

Using our RNAseq data, we studied the TGF- $\beta$ superfamily and its signaling network. We found that Noggin was significantly up-regulated in response to Alk4 downregulation. This finding was confirmed with qPCR in Alk4
ViM-treated muscles (Fig. 7E). As an antagonist of bone morphogenetic protein (BMP) signaling, Noggin prevents binding of BMP ligands to their receptors, thereby blocking the activation of BMP signaling (44). BMP signaling is crucial in maintaining muscle mass, preventing muscle atrophy, and regulating muscle regeneration (45-47). In addition, our attention was drawn to the Fbxo30 gene, which encodes the F-box protein belonging to the F-box-containing complex family of ubiquitin. Fbxo30 was significantly upregulated in response to Alk4 down-regulation (data not shown), and it has been shown to be induced in the atrophying muscles of Smad4-deficient mice (45). 
TABLE 3. Signaling pathways activated/inhibited significantly in response to Alk4 down-regulation using the OncoFinder method

\begin{tabular}{|c|c|c|}
\hline Name & State & $P$ \\
\hline $\begin{array}{l}\text { GSK3 pathway (gene expression via } \\
\text { CTNNB1) }\end{array}$ & Activated & $9.34 \mathrm{E}^{-07}$ \\
\hline GSK3 pathway (b-CTNN degradation) & Activated & $1.02 \mathrm{E}^{-05}$ \\
\hline JAK mStat Pathway (JAK degradation) & Inhibited & $1.02 \mathrm{E}^{-05}$ \\
\hline $\begin{array}{l}\text { Ubiquitin proteasome-dependent } \\
\text { proteolysis pathway }\end{array}$ & Activated & $4.00 \mathrm{E}^{-05}$ \\
\hline $\begin{array}{l}\text { WNT pathway (cell fate proliferation, } \\
\text { differentiation, adhesion and } \\
\text { survival) }\end{array}$ & Unclear & $4.77 \mathrm{E}^{-05}$ \\
\hline CD40 pathway & Activated & $2.17 \mathrm{E}^{-04}$ \\
\hline TNF main pathway & Activated & $2.51 \mathrm{E}^{-04}$ \\
\hline p38 pathway (translation) & Unclear & $3.27 \mathrm{E}^{-04}$ \\
\hline IL-2 pathway (IL-2 gene expression) & Activated & $5.14 \mathrm{E}^{-04}$ \\
\hline SMAD signaling network pathway & Unclear & $7.27 \mathrm{E}^{-04}$ \\
\hline GSK3 pathway (glycogen synthesis) & Inhibited & $1.04 \mathrm{E}^{-03}$ \\
\hline mTOR main pathway & Activated & $1.42 \mathrm{E}^{-03}$ \\
\hline WNT main pathway & Unclear & $1.47 \mathrm{E}^{-03}$ \\
\hline PTEN pathway (apoptosis) & Inhibited & $2.00 \mathrm{E}^{-03}$ \\
\hline GSK3 pathway (protein synthesis) & Inhibited & $2.41 \mathrm{E}^{-03}$ \\
\hline $\begin{array}{l}\text { TNF pathway (gene expression and } \\
\text { cell survival) }\end{array}$ & Activated & $2.41 \mathrm{E}^{-03}$ \\
\hline AKT main pathway & Activated & $2.48 \mathrm{E}^{-03}$ \\
\hline IL-2 main pathway & Activated & $2.88 \mathrm{E}^{-03}$ \\
\hline IGF1R pathway (glycogen synthesis) & Inhibited & $3.91 \mathrm{E}^{-03}$ \\
\hline
\end{tabular}

GSK3, glycogen synthase kinase 3; IGF1R, insulin growth factor- 1 receptor; mTOR, mammalian target of rapamycin; PTEN, phosphatase and tensin homolog; SMAD, mothers against decapentaplegic homo$\log 3 \mathrm{Wnt}$, wingless-type MMTV integration site family.

We also assessed expression of genes involved in atrophic response in $m d x$ gastrocnemius muscles treated with Alk4 or control ViM. In contrast to the finding in WT mice, no significant differences in the atrophic markers Cdkn1a, Murf-1, and Atf4 were found in Alk4 ViM-treated $m d x$ gastrocnemius muscles, whereas Gadd45a was upregulated after 7 wk of Alk4 ViM treatment (Supplemental Fig.S4A). Furthermore, a significant increase in Asns gene expression (low glucose marker) was found in $m d x$ muscles after 1 and 7 wk of Alk4 ViM treatment (Supplemental Fig.S4B). In addition to metabolic changes, a significant up-regulation of UPR after Alk4 down-regulation was demonstrated. A significant increase in Chop gene expression after $7 \mathrm{wk}$ of Alk4 ViM treatment was found with qPCR analysis (Supplemental Fig.S4B). Last, Noggin was also increased in $m d x$ muscles after $7 \mathrm{wk}$ of Alk4 ViM treatment (Supplemental Fig.S4D). These findings suggest that, as in WT muscle, the UPR pathway is activated by Alk4 down-regulation, whereas atrophic pathways are not activated in $m d x$ muscles.

\section{DISCUSSION}

Many research groups have focused on blockage of the MSTN/ACVR2B pathway as a therapy for various types of muscle dystrophies (48). Progress has been made, but it is still being debated whether this blockage can improve muscle function and muscle quality (12, 49-51). MSTN signaling not only negatively regulates muscle growth, but also affects metabolic properties of the muscle, such as oxidative capacity, glucose metabolism, and fat utilization (52). Recently, it has been found that blockage of ACVR2B induces hypertrophy, but is accompanied by increased muscle metabolic myopathy (53).

In the current study, we developed a novel approach to specifically block MSTN signaling, involving targeting the ALK4 receptor with AONs, which is necessary to activate Smad transcription factors. To inhibit ALK4, we developed 2OMePS AONs and ViMs, which specifically target out-of-frame exon 6, generating a premature stop codon in exon 7. A premature stop codon can activate nonsense-mediated decay, leading to Alk4 transcript degradation. However, we cannot rule out that skipping of exon 6, which encodes a crucial part of the kinase domain, would generate a dysfunctional ALK4 protein-lacking kinase domain that would act as a ligand trap.

The sequence-specific approach using AONs has the advantage that it specifically modulates Alk4 expression and does not induce any off-target effects. To our knowledge, there are no other specific ALK4 inhibitors available, and most small molecules inhibit nonrelated protein kinases and related protein kinases, such as ALK5 and ALK7 (54). Indeed, with our approach we showed specific knockdown of Alk4 expression after transfection or injection with Alk4 AONs in cells and in mice. Because of the lack of specific ALK4 antibodies, we were not able to show the effect on protein level. However, the specific inhibition of MSTN signaling and the enhanced myogenic differentiation shown after Alk4 AON transfection in myogenic cells suggest that we achieved functional inhibition of MSTN signaling with Alk4 AON in vitro.

Unexpectedly, Alk4 down-regulation in vivo resulted in a profound, significant decrease in muscle weight. This result contradicts findings from many other groups-that is, an increase in muscle mass in response to MSTN/ ACVR2B blockage $(12,13,49,50,55)$. However, Smad3 depletion decreases muscle mass as well and triggers pronounced muscle atrophy $(56,57)$. Furthermore, Smad3 is essential for normal skeletal muscle growth and muscle regeneration, and depletion of Smad3 increases Mstn expression, thus contributing to muscle atrophy and impaired muscle regeneration. In our Alk4 down-regulation model, we did not detect any increase in Mstn expression (data not shown) suggesting that muscle atrophy is triggered via different mechanism.

\section{The role of ALK4 in muscle regeneration}

To identify the cause of Alk4-knockdown-mediated muscle weight decrease, we first looked at the influence of muscle degeneration/regeneration, because regenerative fibers are smaller and increased regeneration may partially explain the observed drop in muscle weight. The rationale for this approach was the observed increased differentiation after Alk 4 knockdown in vitro. The $m d x$ mice showed increased regenerative areas upon Alk4 AON treatment and a significant overall decrease in fiber size by $\sim 150$ $\mu \mathrm{m}^{2}$. This effect was not found in WT mice, which 
A

Murf-1

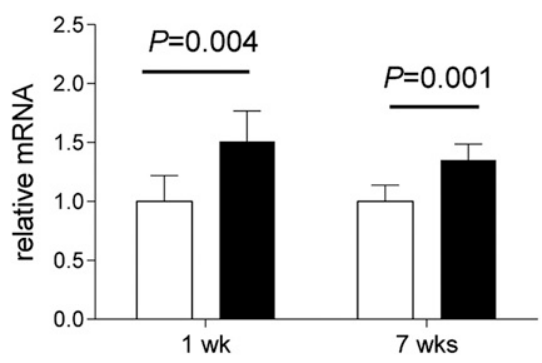

Cdkn1a

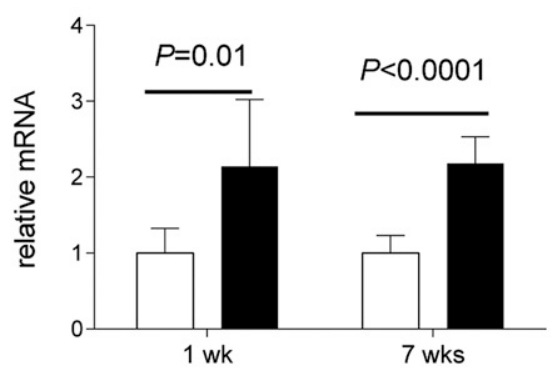

D

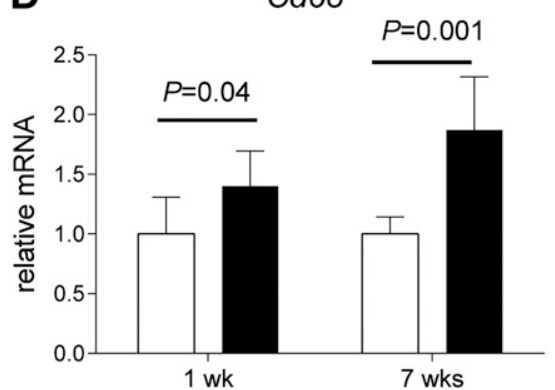

Atf4

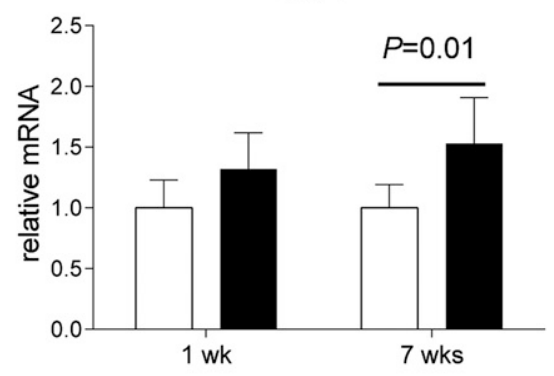

Gadd45a

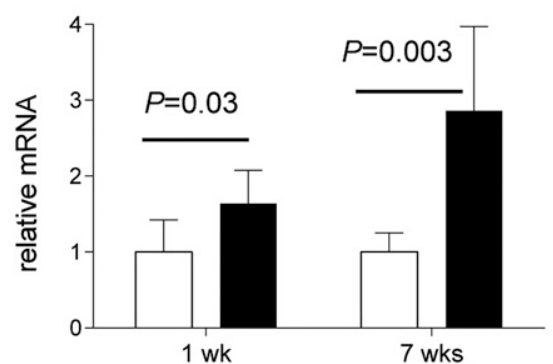

Lgals3

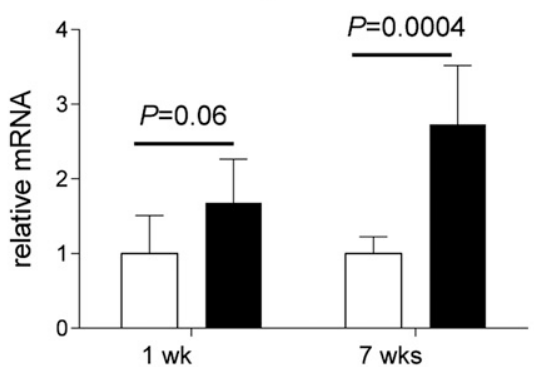

B

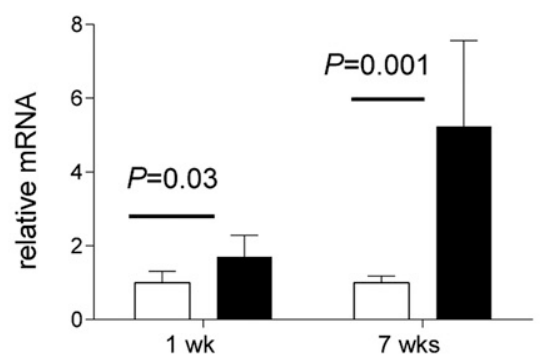

C

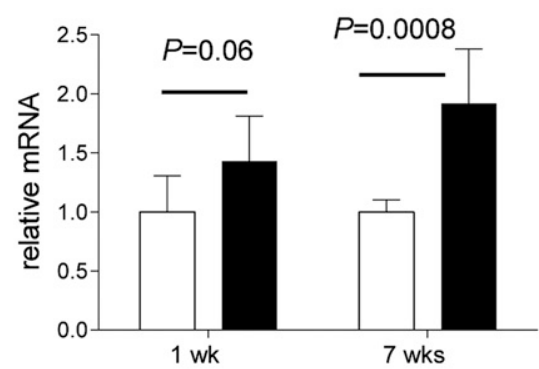

E

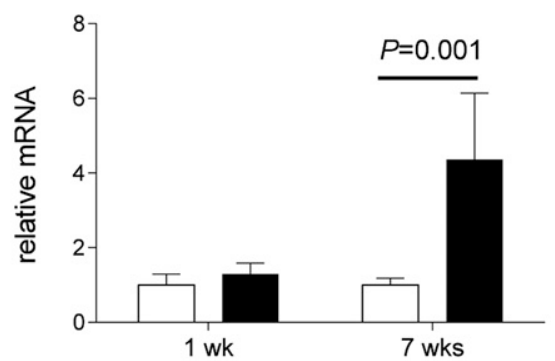

Figure 7. qPCR validation of WT gastrocnemius muscles after Alk4 down-regulation. A) Gene expression of Murf-1, Atf4, Cdkn1a, and Gadd45a was measured with qPCR in WT gastrocnemius muscles. Significant up-regulation of Murf-1, Cdkn1a, and Gadd45a was found in Alk4 ViM-treated muscles at 1 and $7 \mathrm{wk}$. Significant up-regulation of Atf4 was found in treated muscles at $7 \mathrm{wk}$. B) The gene expression of Asns was up-regulated in muscles treated both 1 and $7 \mathrm{wk}$. C) The gene expression of Chop was upregulated in treated muscles at both 1 and $7 \mathrm{wk}$. D) Significant up-regulation of $C d 68$ was found at 1 and 7 wk in $A l k 4$ ViM-treated muscles. Significant up-regulation of Lgals was found at 7 wk in treated muscles. E) The expression of Noggin was up-regulated at $7 \mathrm{wk}$ in Alk4 ViM-treated muscles. All expression data were normalized to Gapdh. Error bars, SD.

however, had a more significant lowering in muscle mass. It should be mentioned that, the regenerative effect in $m d x$ mice was only minor $(1.5 \%$ increase, compared to a $10 \%$ decrease in muscle mass). Thus, increased regeneration does not seem to be the primary cause of the decrease in muscle mass. Seeing that MSTN can affect the metabolic profile of skeletal muscles (52), another possibility thus would be a shift from larger type IIx to smaller type IIa fibers. We found that Alk4 down-regulation led to higher mRNA levels of markers for oxidative endurance fibers and markers for a shift toward an oxidative metabolism and away from glycolytic metabolism. This finding implies that ALK4 controls the metabolic profile of skeletal muscle and that blockage of ALK4 improves oxidative properties, thereby possibly improving the endurance capacity of skeletal muscles. Notably, blockage of the other
MSTN coreceptor ACVR2B had an opposite effect on the metabolic profile [i.e., a shift toward a glucose metabolism, increased muscle fatigability, and mitochondrial dysfunction (53)]. Further work is needed to elucidate the metabolic function of MSTN and its type I and II receptors in healthy and dystrophic models.

\section{The role of ALK4 in muscle atrophy}

RNAseq analysis showed increased gene expression of the key regulators of muscle degradation (Murf-1) and muscle atrophy (Atf4). MuRF-1 is one of the key activators of the ubiquitin proteasome pathway, leading to protein breakdown (40). Murf-1 mRNA is therefore a good biomarker for proteolysis and rapid muscle wasting. Activating 
transcription factor (ATF4) is tightly regulated and activates many genes involved in the cellular response to stress (58). For instance, prolonged food withdrawal increases Atf4 expression, which mediates myofiber atrophy. Furthermore, Atf4-mediated transcriptional regulation is essential for myofiber atrophy (43). Atf4 expression increases the expression of a subset of genes involved in starvation-induced myofiber atrophy. In the present study, this subset of genes-Gadd45a, Cdkn1a, and Ankrd1, together with Atf4 and Murf-1-were up-regulated in Alk4 ViM-treated WT muscle, as evidenced by the RNAseq data and confirmed by qPCR. Taken together, these data suggest that Alk4 down-regulation activates protein degradation via the ubiquitin proteasome pathway and induces starvationinduced muscle atrophy via ATF4 signaling. We confirmed up-regulation of genes involved in myofiber atrophy in WT gastrocnemius muscles upon Alk4 down-regulation. Upregulation of Murf-1 and atrophic genes (Gadd45a, Cdkn1a) was observed as early as $1 \mathrm{wk}$ after Alk4 AON treatment, suggesting a very rapid atrophic response to Alk4 downregulation. In $m d x$ samples, no such effect was found, but an increase in Gadd45a expression was measured after 7 wk of treatment. The discrepancy in atrophic response between $\mathrm{WT}$ and $m d x$ mice can be explained by difference in age ( 3 mo for WT vs. $4 \mathrm{wk}$ for $m d x$ ), in levels of Alk4 downregulation ( $70 \%$ for WT vs. $30 \%$ for $m d x$ ) and by the presence of the dystrophic pathology in $m d x$ mice, which triggers activation of inflammatory, fibrotic, and degenerative/ regenerative pathways.

\section{The role of ALK4 in muscle metabolism and UPR activation}

Our data suggest that decreased ALK4 receptor levels in muscles lead to altered metabolism and low levels of glucose homeostasis, causing amino acid deprivation and muscle starvation. Because of muscle starvation, UPR is activated to recycle proteins, ultimately leading to increased atrophic response and muscle mass loss.

\section{Noggin up-regulation contributes to muscle wasting and regeneration}

Recent findings of a positive role for BMP-mediated signaling in muscle challenged the idea of how the TGF- $\beta$ superfamily and its signaling network regulates the skeletal muscle phenotype (59). Blockage of BMP signaling causes muscle atrophy, reduces muscle mass in MSTNknockout mice (BMP has a dominant role over MSTN) and strongly exacerbates the effects of denervation and food withdrawal (45). In the latter study, muscle atrophy was induced by overexpression of Noggin (BMP antagonist). In our Alk4 down-regulation model, we found that Noggin was significantly up-regulated, and the change resulted in inhibition of BMP signaling. Noggin up-regulation and increase in Fbxo30 mRNA levels may explain the unexpected decrease in muscle mass. We postulate that inhibition of BMP signaling is associated with activation of protein breakdown and the starvation-induced muscle atrophy that we observed in our Alk4 down-regulation model. BMP signaling is also known to regulate muscle regeneration. Overexpression of the BMP antagonist Noggin increases muscle regeneration and improves muscle quality in $m d x$ mice (60). In contrast, BMP was found to be crucial for normal muscle repair after induced muscle injury in a previous study (61). In our Alk4 downregulation model, muscle regeneration was increased, though with a smaller fiber profile, in $m d x$ mice. We postulate that this increase is linked to the inhibition of BMP signaling via Noggin up-regulation. However, more studies on downstream targets of BMP signaling are needed to show the link between Alk4 down-regulation and BMP blockage.

As activins function via the ALK4 receptor in muscles, the effects we observed may be caused by interference with activin signaling. Activins are mediators of both inflammatory and anti-inflammatory activities and initiators of the cytokine cascades that activate an inflammatory response (62). In our Alk4 down-regulation model, we observed Cd68 and Lgals3 up-regulation in WT muscles, which suggests that ALK4 not only affects myofibers but also activates proinflammatory cells such as macrophages (CD68+). In $m d x$ mice, Alk4 down-regulation did not increase gene expression of the inflammatory markers any further, probably because of an already present chronic inflammation caused by dystrophin deficiency. As previously described, Alk4 mRNA is abundant in endothelial cells, and inhibition of MSTN or treatment with ActRIIB inhibitors negatively affects muscle capillarization (53). We studied the effect of Alk4 down-regulation on VEGF signaling, but did not find any differences in $V e g f-A$ and Cd31 gene expression between Alk4 ViM- and control ViM-treated muscles (data not shown). This result suggests that blockage of the ALK4 receptor does not affect capillary formation and function and that muscle starvation and atrophy do not occur because of decreased capillary density and function.

In our study, Alk4 knockdown in $m d x$ mice did not result in overt improvements of the dystrophic phenotype and muscle function. We detected only a small increase in regeneration and in the number of smaller fibers. However, after ALK4 blockage we observed an altered muscle metabolism, leading to metabolic myopathy accompanied by stress responses and amino acid deprivation. It would be worthwhile to study whether these pathways are also induced with MSTN antibodies and ACVR2B knockdown.

In summary, in this study, we showed that one of the key receptors of the MSTN pathway, the ALK4, influences myogenesis and regulates the tight balance between protein synthesis and degradation to maintain muscle mass. Therefore, caution should be used in developing therapies that involve interference in the MSTN/activin pathway. F

\section{ACKNOWLEDGMENTS}

The authors thank Mrs. Laura van Vliet (Leiden University Medical Center) for excellent technical support; Christa Tanganyika-de Winter, Silvana Jirka, Monika Hiller, Nisha Verwey, Michel Villerius, and Ivo Fokkema (Leiden University Medical Center) for excellent technical help; Dr. Pietro 
Spitalli, Prof. Dr. Dorien Peters, Prof. Dr. Gert-Jan van Ommen, and Prof. Dr. Silvère van der Maarel (Leiden University Medical Center) for valuable input; Dr. Philippe Bertolino (Centre de Recherche en Cancérologie de Lyon, Lyon, France) for valuable collaboration; BioMarin Nederland BV for providing the Alk4 and scrambled control AONs; and K. Hagoort (Erasmus University Medical Center, Rotterdam, The Netherlands) for critical reading of the manuscript. This work was supported by grants from ZonMw (Project 113302001) and NeurOmics (FP7, Agreement 2012-305121). The authors declare no conflicts of interest.

\section{AUTHOR CONTRIBUTIONS}

S. Pasteuning-Vuhman performed research and implemented suggestions; J. W. Boertje-van der Meulen performed in vitro and in vivo experiments; M. van Putten performed in vitro TA physiology and wrote related paragraphs; M. Overzier performed intramuscular injections and muscle isolations; P. ten Dijke and W. M. Hoogaars designed the research; S. M. Kiełbasa and W. Arindrarto analyzed RNA-seq data; R. Wolterbeek performed statistical analyses for fiber size distribution; K. V. Lezhnina performed pathway analyses using the OncoFinder method; I. V. Ozerov and A. M. Aliper developed the OncoFinder method; A. Aartsma-Rus designed the research and coordinated the paper-writing process; C. J. M. Loomans performed and helped design the research. S. Pasteuning-Vuhman wrote the first draft of the paper, and all remaining authors edited the paper.

\section{REFERENCES}

1. Kambadur, R., Sharma, M., Smith, T. P., and Bass, J. J. (1997) Mutations in myostatin (GDF8) in double-muscled Belgian Blue and Piedmontese cattle. Genome Res. 7, 910-916

2. McPherron, A. C., Lawler, A. M., and Lee, S. J. (1997) Regulation of skeletal muscle mass in mice by a new TGF-beta superfamily member. Nature 387, 83-90

3. McPherron, A. C., and Lee, S. J. (1997) Double muscling in cattle due to mutations in the myostatin gene. Proc. Natl. Acad. Sci. USA 94, 12457-12461

4. Rebbapragada, A., Benchabane, H., Wrana, J. L., Celeste, A. J., and Attisano, L. (2003) Myostatin signals through a transforming growth factor beta-like signaling pathway to block adipogenesis. Mol. Cell. Biol. 23, 7230-7242

5. Lee, S. J., and McPherron, A. C. (2001) Regulation of myostatin activity and muscle growth. Proc. Natl. Acad. Sci. USA 98, 93069311

6. Ten Dijke, P., and Hill, C. S. (2004) New insights into TGF-beta-Smad signalling. Trends Biochem. Sci. 29, 265-273

7. Li, Z. B., Kollias, H. D., and Wagner, K. R. (2008) Myostatin directly regulates skeletal muscle fibrosis. J. Biol. Chem. 283, 1937119378

8. Wagner, K. R. (2005) Muscle regeneration through myostatin inhibition. Curr. Opin. Rheumatol. 17, 720-724

9. Nozaki, M., Li, Y., Zhu, J., Ambrosio, F., Uehara, K., Fu, F. H., and Huard, J. (2008) Improved muscle healing after contusion injury by the inhibitory effect of suramin on myostatin, a negative regulator of muscle growth. Am. J. Sports Med. 36, 2354-2362

10. Emery, A. E. (2002) Muscular dystrophy into the new millennium. Neuromuscul. Disord. 12, 343-349

11. Mendell, J. R., Shilling, C., Leslie, N. D., Flanigan, K. M., al-Dahhak, R., Gastier-Foster, J., Kneile, K., Dunn, D. M., Duval, B., Aoyagi, A., Hamil, C., Mahmoud, M., Roush, K., Bird, L., Rankin, C., Lilly, H., Street, N., Chandrasekar, R., and Weiss, R. B. (2012) Evidence-based path to newborn screening for Duchenne muscular dystrophy. Ann. Neurol. 71, 304-313
12. Morine, K. J., Bish, L. T., Selsby, J. T., Gazzara, J. A., Pendrak, K. Sleeper, M. M., Barton, E. R., Lee, S. J., and Sweeney, H. L. (2010) Activin IIB receptor blockade attenuates dystrophic pathology in a mouse model of Duchenne muscular dystrophy. Muscle Nerve $\mathbf{4 2}$ 722-730

13. Roth, S. M., and Walsh, S. (2004) Myostatin: a therapeutic target for skeletal muscle wasting. Curr. Opin. Clin. Nutr. Metab. Care 7, 259-263

14. Wagner, K. R., McPherron, A. C., Winik, N., and Lee, S. J. (2002) Loss of myostatin attenuates severity of muscular dystrophy in mdx mice. Ann. Neurol. 52, 832-836

15. Wagner, K. R., Fleckenstein, J. L., Amato, A. A., Barohn, R. J., Bushby, K., Escolar, D. M., Flanigan, K. M., Pestronk, A., Tawil, R., Wolfe, G. I., Eagle, M., Florence, J. M., King, W. M., Pandya, S., Straub, V., Juneau, P., Meyers, K., Csimma, C., Araujo, T., Allen, R., Parsons, S. A., Wozney, J. M., Lavallie, E. R., and Mendell, J. R. (2008) A phase I/ IItrial of MYO-029 in adult subjects with muscular dystrophy. Ann. Neurol. 63, 561-571

16. Attie, K. M., Borgstein, N. G., Yang, Y., Condon, C. H., Wilson, D. M., Pearsall, A. E., Kumar, R., Willins, D. A., Seehra, J. S., and Sherman, M. L. (2013) A single ascending-dose study of muscle regulator ACE031 in healthy volunteers. Muscle Nerve 47, 416-423

17. Kemaladewi, D. U., de Gorter, D. J., Aartsma-Rus, A., van Ommen, G. J., ten Dijke, P., 't Hoen, P. A., and Hoogaars, W. M. (2012) Cell-type specific regulation of myostatin signaling. FASEB J. 26, 1462-1472

18. Kemaladewi, D. U., Pasteuning, S., van der Meulen, J. W., van Heiningen, S. H., van Ommen, G. J., ten Dijke, P., Aartsma-Rus, A., 't Hoen, P. A., and Hoogaars, W. M. (2014) Targeting TGF- $\beta$ signaling by antisense oligonucleotide-mediated knockdown of TGF$\beta$ type I receptor. Mol. Ther. Nucleic Acids 3, e156

19. Beauchamp, J. R., Heslop, L., Yu, D. S., Tajbakhsh, S., Kelly, R. G., Wernig, A., Buckingham, M. E., Partridge, T. A., and Zammit, P. S. (2000) Expression of CD34 and Myf5 defines the majority of quiescent adult skeletal muscle satellite cells. J. Cell Biol. 151, $1221-1234$

20. Ono, Y., Gnocchi, V. F., Zammit, P. S., and Nagatomi, R. (2009) Presenilin-1 acts via Id1 to regulate the function of muscle satellite cells in a gamma-secretase-independent manner. J. Cell Sci. 122, 4427-4438

21. Sharp, P. S., Bye-a-Jee, H., and Wells, D. J. (2011) Physiological characterization of muscle strength with variable levels of dystrophin restoration in mdx mice following local antisense therapy. Mol. Ther. 19, 165-171

22. Spitali, P., Heemskerk, H., Vossen, R. H., Ferlini, A., den Dunnen, J. T., 't Hoen, P. A., and Aartsma-Rus, A. (2010) Accurate quantification of dystrophin mRNA and exon skipping levels in duchenne muscular dystrophy. Lab. Invest. 90, 1396-1402

23. Goeman, J. J., van de Geer, S. A., de Kort, F., and van Houwelingen, H. C. (2004) A global test for groups of genes: testing association with a clinical outcome. Bioinformatics 20, 93-99

24. Goeman, J. J., Oosting, J., Cleton-Jansen, A. M., Anninga, J. K., and van Houwelingen, H. C. (2005) Testing association of a pathway with survival using gene expression data. Bioinformatics 21, 1950-1957

25. Buzdin, A. A., Zhavoronkov, A. A., Korzinkin, M. B., Roumiantsev, S. A., Aliper, A. M., Venkova, L. S., Smirnov, P. Y., and Borisov, N. M. (2014) The OncoFinder algorithm for minimizing the errors introduced by the high-throughput methods of transcriptome analysis. Front. Mol. Biosci. 1, 8

26. Buzdin, A. A., Zhavoronkov, A. A., Korzinkin, M. B., Venkova, L. S., Zenin, A. A., Smirnov, P. Y., and Borisov, N. M. (2014) Oncofinder, a new method for the analysis of intracellular signaling pathway activation using transcriptomic data. Front. Genet. 5, 55

27. Van Putten, M., de Winter, C., van Roon-Mom, W., van Ommen, G.J., 't Hoen, P. A., and Aartsma-Rus, A. (2010) A 3 months mild functional test regime does not affect disease parameters in young $\mathrm{mdx}$ mice. Neuromusc. Disord. 20, 273-280

28. Van Putten, M., Kumar, D., Hulsker, M., Hoogaars, W. M., Plomp, J.J., van Opstal, A., van Iterson, M., Admiraal, P., van Ommen, G. J., 't Hoen, P. A., and Aartsma-Rus, A. (2012) Comparison of skeletal muscle pathology and motor function of dystrophin and utrophin deficient mouse strains. Neuromusc. Disord. 22, 406-417

29. Smith, L. R., and Barton, E. R. (2014) SMASH: semi-automatic muscle analysis using segmentation of histology: a MATLAB application. Skelet. Muscle 4, 21

30. Aartsma-Rus, A. (2012) Overview on AON design. Methods Mol. Biol. 867, 117-129

31. Onwuegbusi, B. A., Rees, J. R., Lao-Sirieix, P., and Fitzgerald, R. C. (2007) Selective loss of TGFbeta Smad-dependent signalling prevents 
cell cycle arrest and promotes invasion in oesophageal adenocarcinoma cell lines. PLoS One 2, e177

32. Liu, M., Yue, Y., Harper, S. Q., Grange, R. W., Chamberlain, J. S., and Duan, D. (2005) Adeno-associated virus-mediated microdystrophin expression protects young mdx muscle from contraction-induced injury. Mol. Ther. 11, 245-256

33. Zhao, G., Jeoung, N. H., Burgess, S. C., Rosaaen-Stowe, K. A., Inagaki, T., Latif, S., Shelton, J. M., McAnally, J., Bassel-Duby, R., Harris, R. A., Richardson, J. A., and Kliewer, S. A. (2008) Overexpression of pyruvate dehydrogenase kinase 4 in heart perturbs metabolism and exacerbates calcineurin-induced cardiomyopathy. Am.J. Physiol. Heart Circ. Physiol. 294, H936-H943

34. Guzun, R., Gonzalez-Granillo, M., Karu-Varikmaa, M., Grichine, A., Usson, Y., Kaambre, T., Guerrero-Roesch, K., Kuznetsov, A., Schlattner, U., and Saks, V. (2012) Regulation of respiration in muscle cells in vivo by VDAC through interaction with the cytoskeleton and MtCK within mitochondrial interactosome. Biochim. Biophys. Acta 1818, 1545-1554

35. Love, M. I., Huber, W., and Anders, S. (2014) Moderated estimation of fold change and dispersion for RNA-seq data with DESeq2. Genome Biol. 15, 550

36. Ritchie, M. E., Phipson, B., Wu, D., Hu, Y., Law, C. W., Shi, W., and Smyth, G. K. (2015) limma powers differential expression analyses for RNA-sequencing and microarray studies. Nucleic Acids Res. 43, e47

37. McCarthy, D. J., Chen, Y., and Smyth, G. K. (2012) Differential expression analysis of multifactor RNA-Seq experiments with respect to biological variation. Nucleic Acids Res. 40, 4288-4297

38. Song, Z., Jin, R., Yu, S., Rivet, J. J., Smyth, S. S., Nanda, A., Granger, D. N., and Li, G. (2011) CD40 is essential in the upregulation of TRAF proteins and NF-kappaB-dependent proinflammatory gene expression after arterial injury. PLoS One 6, e23239

39. Han, A. A., Currie, H. N., Loos, M. S., Vrana, J. A., Fabyanic, E. B., Prediger, M.S., and Boyd, J. W. (2016) Spatiotemporal phosphoprotein distribution and associated cytokine response of a traumatic injury. Cytokine 79, 12-22

40. Rom, O., and Reznick, A. Z. (2015) The role of E3 ubiquitin-ligases MuRF-1 and MAFbx in loss of skeletal muscle mass. Free Radic. Biol. Med.

41. Yuan, L., Han, J., Meng, Q., Xi, Q., Zhuang, Q., Jiang, Y., Han, Y., Zhang, B., Fang, J., and Wu, G. (2015) Muscle-specific E3 ubiquitin ligases are involved in muscle atrophy of cancer cachexia: an in vitro and in vivo study. Oncol. Rep. 33, 2261-2268

42. Ebert, S. M., Dyle, M. C., Kunkel, S. D., Bullard, S. A., Bongers, K. S., Fox, D. K., Dierdorff, J. M., Foster, E. D., and Adams, C. M. (2012) Stress-induced skeletal muscle Gadd45a expression reprograms myonuclei and causes muscle atrophy. J. Biol. Chem. 287, 27290-27301

43. Ebert, S. M., Monteys, A. M., Fox, D. K., Bongers, K. S., Shields, B. E., Malmberg, S. E., Davidson, B. L., Suneja, M., and Adams, C. M. (2010) The transcription factor ATF4 promotes skeletal myofiber atrophy during fasting. Mol. Endocrinol. 24, 790-799

44. Mulloy, B., and Rider, C. C. (2015) The bone morphogenetic proteins and their antagonists. Vitam. Horm. 99, 63-90

45. Sartori, R., Schirwis, E., Blaauw, B., Bortolanza, S., Zhao, J., Enzo, E., Stantzou, A., Mouisel, E., Toniolo, L., Ferry, A., Stricker, S., Goldberg, A. L., Dupont, S., Piccolo, S., Amthor, H., and Sandri, M. (2013) BMP signaling controls muscle mass. Nat. Genet. 45, 1309-1318

46. Ono, Y., Calhabeu, F., Morgan, J. E., Katagiri, T., Amthor, H., and Zammit, P.S. (2011) BMP signalling permits population expansion by preventing premature myogenic differentiation in muscle satellite cells. Cell Death Differ. 18, 222-234

47. Winbanks, C. E., Chen, J. L., Qian, H., Liu, Y., Bernardo, B. C., Beyer, C., Watt, K. I., Thomson, R. E., Connor, T., Turner, B. J., McMullen, J. R., Larsson, L., McGee, S. L., Harrison, C. A., and Gregorevic, P. (2013) The bone morphogenetic protein axis is a positive regulator of skeletal muscle mass. J. Cell Biol. 203, 345-357
48. Amthor, H., and Hoogaars, W. M. (2012) Interference with myostatin/ ActRIIB signaling as a therapeutic strategy for Duchenne muscular dystrophy. Curr. Gene Ther. 12, 245-259

49. Amthor, H., Macharia, R., Navarrete, R., Schuelke, M., Brown, S. C., Otto, A., Voit, T., Muntoni, F., Vrbóva, G., Partridge, T., Zammit, P., Bunger, L., and Patel, K. (2007) Lack of myostatin results in excessive muscle growth but impaired force generation. Proc. Natl. Acad. Sci. USA 104, 1835-1840

50. Cadena, S. M., Tomkinson, K. N., Monnell, T. E., Spaits, M. S., Kumar, R., Underwood, K. W., Pearsall, R. S., and Lachey, J. L. (2010) Administration of a soluble activin type IIB receptor promotes skeletal muscle growth independent of fiber type. J.Appl. Physiol. (1985) 109, 635-642

51. Matsakas, A., Mouisel, E., Amthor, H., and Patel, K. (2010) Myostatin knockout mice increase oxidative muscle phenotype as an adaptive response to exercise. J. Muscle Res. Cell Motil. 31, 111-125

52. Rahimov, F., King, O. D., Warsing, L. C., Powell, R. E., Emerson, C. P., Jr., Kunkel, L. M., and Wagner, K. R. (2011) Gene expression profiling of skeletal muscles treated with a soluble activin type IIB receptor. Physiol. Genomics 43, 398-407

53. Relizani, K., Mouisel, E., Giannesini, B., Hourde, C., Patel, K. Morales Gonzalez, S., Julich, K., Vignaud, A., Pietri-Rouxel, F., Fortin, D., Garcia, L., Blot, S., Ritvos, O., Bendahan, D., Ferry, A., Ventura-Clapier, R., Schuelke, M., and Amthor, H. (2014) Blockade of ActRIIB signaling triggers muscle fatigability and metabolic myopathy. Mol. Ther. 22, 1423-1433

54. Vogt, J., Traynor, R., and Sapkota, G. P. (2011) The specificities of small molecule inhibitors of the TGFß and BMP pathways. Cell. Signal. 23, 1831-1842

55. Han, H. Q., Zhou, X., Mitch, W. E., and Goldberg, A. L. (2013) Myostatin/activin pathway antagonism: molecular basis and therapeutic potential. Int. J. Biochem. Cell Biol. 45, 2333-2347

56. Ge, X., McFarlane, C., Vajjala, A., Lokireddy, S., Ng, Z. H., Tan, C. K. Tan, N. S., Wahli, W., Sharma, M., and Kambadur, R. (2011) Smad3 signaling is required for satellite cell function and myogenic differentiation of myoblasts. Cell Res. 21, 1591-1604

57. Ge, X., Vajjala, A., McFarlane, C., Wahli, W., Sharma, M., and Kambadur, R. (2012) Lack of Smad3 signaling leads to impaired skeletal muscle regeneration. Am. J. Physiol. Endocrinol. Metab. 303, E90-E102

58. Bongers, K. S., Fox, D. K., Ebert, S. M., Kunkel, S. D., Dyle, M. C., Bullard, S. A., Dierdorff, J. M., and Adams, C. M. (2013) Skeletal muscle denervation causes skeletal muscle atrophy through a pathway that involves both Gadd45a and HDAC4. Am. J. Physiol. Endocrinol. Metab. 305, E907-E915

59. Sartori, R., Gregorevic, P., and Sandri, M. (2014) TGFbeta and BMP signaling in skeletal muscle: potential significance for muscle-related disease. Trends Endocrinol. Metab. TEM 25, 464-471

60. Shi, S., Hoogaars, W. M., de Gorter, D. J., van Heiningen, S. H., Lin, H. Y., Hong, C. C., Kemaladewi, D. U., Aartsma-Rus, A., ten Dijke, P., and 't Hoen, P. A. (2011) BMP antagonists enhance myogenic differentiation and ameliorate the dystrophic phenotype in a DMD mouse model. Neurobiol. Dis. 41, 353-360

61. Clever, J. L., Sakai, Y., Wang, R. A., and Schneider, D. B. (2010) Inefficient skeletal muscle repair in inhibitor of differentiation knockout mice suggests a crucial role for BMP signaling during adult muscle regeneration. Am. J. Physiol. Cell Physiol. 298, C1087-C1099

62. Yaden, B. C., Wang, Y. X., Wilson, J. M., Culver, A. E., Milner, A., Datta-Mannan, A., Shetler, P., Croy, J. E., Dai, G., and Krishnan, V. (2014) Inhibition of activin A ameliorates skeletal muscle injury and rescues contractile properties by inducing efficient remodeling in female mice. Am. J. Pathol. 184, 1152-1166

Received for publication June 20, 2016. Accepted for publication September 22, 2016. 